\title{
Identifying persistent temperature inversion events in a subalpine basin using radon-222
}

\author{
Dafina Kikaj $^{1,2}$, Janja Vaupotič ${ }^{2}$, and Scott D. Chambers ${ }^{3}$ \\ ${ }^{1}$ Jožef Stefan International Postgraduate School, Jamova cesta 39, 1000 Ljubljana, Slovenia \\ ${ }^{2}$ Jožef Stefan Institute, Department of Environmental Sciences, Jamova cesta 39, 1000 Ljubljana, Slovenia \\ ${ }^{3}$ ANSTO, Environmental Research, Locked Bag 2001, Kirrawee DC, NSW 2232, Australia
}

Correspondence: Dafina Kikaj (dafina.kikaj@ijs.si)

Received: 16 November 2018 - Discussion started: 22 February 2019

Revised: 15 May 2019 - Accepted: 17 July 2019 - Published: 21 August 2019

\begin{abstract}
One year of meteorological and atmospheric radon observations in a topographically complex subalpine basin are used to identify persistent temperature inversion (PTI) events. PTI events play a key role in public health due to the accumulation of urban pollutants that they cause. Two techniques are compared: a new radon-based method (RBM), based on single-height ${ }^{222} \mathrm{Rn}$ measurements from a single centrally located station, and an existing pseudo-vertical temperature gradient method (TGM) based on observations from eight weather stations around the subalpine basin. The RBM identified six PTI events (four in winter, two in autumn), a subset of the 17 events identified by the TGM. The RBM was more consistent in its identification of PTI events for all seasons and more selective of persistent strongly stable conditions. The comparatively poor performance of the TGM was attributed to seasonal inconsistencies in the validity of the method's key assumptions (influenced by mesoscale processes, such as local drainage flows, nocturnal jets, and intermittent turbulence influence) and a lack of snow cover in the basin for the 2016-2017 winter period. Corresponding meteorological quantities for RBM PTI events (constituting $27 \%$ of the autumn-winter cold season) were well characterized. PTI wind speeds in the basin were consistently low over the whole diurnal cycle (typically $0.2-0.6 \mathrm{~m} \mathrm{~s}^{-1}$ ). Suitability of the two techniques for air quality assessment was compared using hourly $\mathrm{PM}_{10}$ observations. Peak $\mathrm{PM}_{10}$ concentrations for winter (autumn) PTI events were underestimated by $13 \mu \mathrm{g} \mathrm{m}^{-3}\left(11 \mu \mathrm{g} \mathrm{m}^{-3}\right)$ by the TGM compared with the RBM. Only the RBM indicated that nocturnal hourly mean $\mathrm{PM}_{10}$ values in winter PTI events can exceed $100 \mu \mathrm{g} \mathrm{m}^{-3}$, the upper threshold of low-level short-term $\mathrm{PM}_{10}$ exposure
\end{abstract}

according to World Health Organization guidelines. The efficacy, simplicity, and cost effectiveness of the RBM for identifying PTI events has the potential to make it a powerful tool for urban air quality management in complex terrain regions, for which it adds an additional dimension to contemporary atmospheric stability classification tools. Furthermore, the long-term consistency of the radon source function will enable the RBM to be used in the same way in future studies, enabling the relative magnitude of PTI events to be gauged, which is expected to assist with the assessment of public health risks.

\section{Introduction}

Urban air pollution is one of the main environmental health risks in Europe (EEA, 2017; WHO, 2014). It derives from aerosols and/or trace gases of natural (e.g., sandstorms, volcanos, forest fires, and ocean spray) or anthropogenic origin (e.g., biomass burning, power generation, transport, and industry) (Beeston et al., 2011; Ferrario et al., 2008; Langmann et al., 2012; Miranda et al., 2015; Pey et al., 2013; Vardoulakis and Kassomenos, 2008). Public health effects can be acute or chronic in nature, and include respiratory illnesses, cardiovascular disorders, conjunctivitis, skin irritations, meningococcal meningitis, valley fever, and even mortality (Goudie, 2014; Griffin, 2005; Highwood and Kinnersley, 2006; Pope and Dockery, 2006). With public health in mind, the World Health Organization (WHO) identified numerous "criteria pollutants" in urban regions for which they have recommended guidelines on concentrations and/or du- 
ration (the Air Quality Directive; EEA, 2017). An air pollution event is considered to have occurred when the concentration of one or more of the criteria pollutants exceeds the guideline value for longer than the specified duration threshold. Such pollution events can be of short duration (1-12 h, day or night) or, under certain conditions, they can persist for days to weeks.

Urban air quality can be influenced by remote, regional, or local processes, depending on the prevailing meteorology (Kukkonen et al., 2005). The particular focus of this study is on pollution events arising as a result of local anthropogenic emissions, the effects of which are exacerbated under specific synoptic weather conditions: cold-season anticyclones. Anticyclonic weather conditions are associated with relatively calm winds and clear skies, due to regional-scale subsidence. In summer, anticyclonic conditions can result in daytime pollution events as a result of rapid secondary-pollutant formation, or nighttime pollution events, when strong radiative cooling results in the formation of shallow, poorly mixed inversion layers. Such pollution events usually end abruptly each morning shortly after the onset of convective mixing as a result of intense sunlight on dry surfaces. In such cases, near-surface concentrations of primary emissions drop $\sim 50 \%$ from peak values by midmorning and reach their minimum values in the early afternoon when the atmospheric boundary layer (ABL) is deep and uniformly mixed (Chambers et al., 2015). In winter, however, day lengths are shorter, sun angles lower, and surfaces wet or frozen. In topographically complex regions, when wind speeds and day length can be even further reduced, and katabatic flows down the basin walls result in the "pooling" of cold air, large-scale subsidence associated with slow-moving or stagnant anticyclonic systems can inhibit the daytime mixing that usually disperses accumulated nocturnal pollution, resulting in air pollution events that can persist for days to weeks (Baasandorj et al., 2017; Cuxart et al., 2006; Kassomenos and Koletsis, 2005). Here we refer to such extended periods of severe air pollution as persistent temperature inversion (PTI) events.

In light of the above, the ability to reliably identify PTI events and objectively quantify their magnitude is important for improved understanding of pollutant concentration variability, assessing potential health impacts on residents, and developing new mitigation measures for air pollution in such complex topographical regions. Unfortunately, there have been relatively few observational studies of PTI events (Clements et al., 2003; Dorninger et al., 2011; Lareau et al., 2013; Lehner et al., 2015; Silcox et al., 2012). To date, this lack of observational studies has mainly been due to the difficulty in making the necessary meteorological measurements within the topographically challenging regions (Yao and Zhong, 2009). Furthermore, such studies often require the deployment of sophisticated instrumentation (e.g., radiosondes, tethered balloons, masts, or aircraft), which is typically expensive and labor intensive to operate (Baasandorj et al., 2017).
The first European field campaign to target PTI events took place in the Chamonix-Mont-Blanc valley, in JanuaryFebruary 2015. This study was motivated by the anomalously high pollution concentrations frequently recorded there. The comprehensive suite of meteorological and chemical observations made throughout the campaign has been described by Chemel et al. (2016). A meteorological approach, based on differences between air temperatures from automatic weather stations at various elevations of the sidewalls of the valley, was used to characterize the stable nocturnal conditions (Dorninger et al., 2011; Whiteman et al., 2004) based on the assumption of horizontally homogenous air temperature. The same pseudo-vertical temperature gradient method was employed by Largeron and Staquet (2016a) in the French Alps to detect PTI events throughout the cold season (November 2006 to February 2007). There are, however, a variety of mesoscale processes that have the potential to disrupt the vertical temperature profile and its horizontal homogeneity (including local drainage flows, nocturnal jets, and intermittent turbulence) (Whiteman et al., 2004; Williams et al., 2013). Such influences can complicate the interpretation of pseudovertical temperature gradients derived from stations of contrasting elevations on valley or basin walls, depending on their particular spatial locations.

By contrast, measurement of a surface-emitted atmospheric tracer with appropriate physical properties (e.g., simple source and sink characteristics), which responds directly to atmospheric mixing processes, has the potential to provide a more consistent and representative method by which to identify PTI events. Such a method should be uniformly applicable, allowing seasonal changes in the number and duration of such events to be determined. Furthermore, once a representative number of events have been identified, seasonally dependent threshold concentrations of the tracer could be determined to help gauge the severity of the inversion events and characterize the meteorological conditions with which they are associated. The naturally occurring radioactive gas radon $\left({ }^{222} \mathrm{Rn}\right)$ is an ideal candidate for this task. The use of radon as a tracer in atmospheric studies dates back from the early 1900s (Eve, 1908; Satterly, 1910; Wigand and Wenk, 1928; Wright and Smith, 1915). In particular, however, radon has achieved considerable credibility in the field of atmospheric science as an indicator of vertical mixing and transport near the Earth's surface from the 1960s until present (Moses et al., 1960; Kirichenko, 1962; Cohen et al., 1972; Allegrini et al., 1994; Perrino et al., 2001; Sesana et al., 2003; Galmarini, 2006; Avino and Manigrasso, 2008; Chambers et al., 2011, 2015, 2019; Williams et al., 2011, 2013, 2016; Pitari et al., 2014; Wang et al., 2016).

Radon concentrations exhibit a high degree of variability on hourly to seasonal timescales. The majority of this variability is attributable to processes occurring at diurnal, synoptic, and seasonal timescales. Other influences, such as those arising from mesoscale motions, or the effects of geographical variability in soil characteristics, rainfall, wind 
speed, and atmospheric pressure on the radon source function (Chambers et al., 2011; Etiope and Martinelli, 2002; Karstens et al., 2015; Levin et al., 2002; Mazur and Kozak, 2014; Salzano et al., 2016, 2018; Szegvary et al., 2007, 2009; Zhuo et al., 2008), are of secondary significance and random in nature, so they typically average out in long-term (seasonal) statistics. The PTI identification technique developed in this study necessitates the ability to characterize and separate the different temporal scales contributing to the variability observed in a radon time series.

Seasonal variability of radon concentrations is contributed to by long-term changes in (i) air mass fetch, (ii) radon source function (through average soil moisture, snow cover, or soil freezing) (Salzano et al., 2016, 2018; Szegvary et al., 2007, 2009; Zhuo et al., 2008), (iii) day length, and (iv) mean atmospheric boundary layer depth (higher in summer, lower in winter), brought about by the annual solar cycle. Synoptic variability (timescale $\leq 2$ weeks) is mainly attributable to short-term changes in air mass fetch, boundary layer depth, and ventilation of the boundary layer, brought about by the passage of synoptic weather systems. In this case, variability of the radon source function over the air masses' recent fetch can have a greater influence on observed concentrations than the local radon source function at the measurement site. Diurnal variability, on the other hand, is primarily attributable to changes in the atmospheric mixing state (i.e., mixing depth or "stability"), and the strength of the local radon source function.

The diurnal radon cycle is characterized by a midafternoon minimum (the magnitude of which is related to the air masses' fetch history) and a nocturnal maximum near dawn (when the atmospheric mixing depth is shallowest). The amplitude of the diurnal radon cycle is directly related to the degree to which near-surface turbulent mixing is suppressed each night. Synoptic cycles of the afternoon minimum radon concentrations can be analogous to the diurnal radon cycle, but on longer timescales. These cycles are characterized by minimum values when gradient winds are strong (or terrestrial fetch is limited), and maximum values when gradient winds are low and there is subsidence (or during extended periods of terrestrial fetch, including stagnation episodes). In the warmer months, when days are convective and nights are stable, diurnal cycle amplitudes exceed synoptic cycle amplitudes. In the colder months, however, the amplitude of the synoptic cycle can be comparable to, or even greater than, that of the diurnal cycle. This seasonal change in relative amplitudes of the diurnal and synoptic radon cycles forms the basis of our method to identify PTI events.

The aims of this study are to use the first year of continuous joint atmospheric radon and meteorological measurements in a subalpine basin (Ljubljana, Slovenia) to (i) develop a seasonally independent radon-based method to reliably identify persistent temperature inversion events in complex topographic regions; (ii) compare the performance of the radon-based scheme to that of a previously published pseudo-vertical temperature gradient method for identifying PTI events over the whole year; (iii) investigate the seasonality of PTI event occurrence in the subalpine basin; and (iv) characterize the local meteorological conditions (air temperature, relative humidity, cloud cover, wind speed, wind direction, and precipitation) associated with PTI events, as well as discuss the implications of these conditions for urban air quality using hourly urban $\mathrm{PM}_{10}$ observations as an example.

\section{Methodology}

\subsection{Radon as a tracer of atmospheric transport and mixing}

${ }^{222} \mathrm{Rn}$ (hereafter radon) is the gaseous decay product of ${ }^{226} \mathrm{Ra}$ (radium), a member of the ${ }^{238} \mathrm{U}$ (uranium) chain, which is ubiquitous all over the Earth's crust. Radon is fairly uniformly distributed on local to regional scales ( 1 atom $\mathrm{cm}^{-2} \mathrm{~s}^{-1} \pm 25 \%$; Jacob et al., 1997; Karstens et al., 2015), and has a source function that is $2-3$ orders of magnitude greater from unsaturated land surfaces than from the open ocean (Schery and Huang, 2004). Once emitted to the atmosphere radon is directly influenced by the meteorological processes that regulate turbulent mixing, namely, vertical and horizontal components of dispersion. Being an inert gas, radon does not chemically react with other atmospheric constituents and its low solubility makes it unlikely to be washed out by rainfall. Consequently, it is eliminated from the atmosphere predominantly by radioactive decay (half-life $3.82 \mathrm{~d}$ ). While radon's short half-life prevents it from accumulating in the atmosphere greater than synoptic timescales, it is possible to track air masses that have been in contact with terrestrial surfaces over the ocean, or within the troposphere, for 2-3 weeks, enabling it to carry important geophysical information over long distances. Since radon's half-life is much greater than mixing timescales of the atmospheric boundary layer, and since radon is still relatively conservative (within $5 \%-10 \%$ ) over the course of a whole night, radon is an appropriate atmospheric tracer for near-surface mixing studies from hourly to nightly timescales. Furthermore, based on the relatively small fraction of terrestrial surfaces occupied by urbanization, at the regional scale radon's terrestrial source function is not significantly affected by human activity.

\subsection{Measurement sites and surroundings}

The Ljubljana subalpine basin site $\left(\mathrm{SAB} ; 46.05^{\circ} \mathrm{N}, 14.51^{\circ} \mathrm{E}\right.$; $299 \mathrm{~m}$ above sea level, $\mathrm{m}$ a.s.l.) is in the capital city of Slovenia, which has a population of around 280000 . The city's climate, classified as temperate and continental, is typical of southern European subalpine regions. Air temperatures exhibit a distinct seasonal cycle, with daily means reaching a maximum of $22^{\circ} \mathrm{C}$ in summer and a minimum of $0^{\circ} \mathrm{C}$ in winter. Prevailing winds for the region are NE, NNE, and 
ENE, and the rainfall distribution is irregular, peaking in summer (ARSO, 2017).

The SAB is surrounded by peaks of the Julian and Kamnik-Savinje alps (Vrhovec, 1990). To the north the region is bounded by the Julian and Kamnik-Savinje alps (highest peaks: Grintovec $2558 \mathrm{~m}$ and Krvavec $1742 \mathrm{~m}$ ), to the west the Šmarna Gora and Rašica hills connect to the Polhov Gradec hills (highest peak: Pasja Ravan, $1019 \mathrm{~m}$ ), and to the east there are the Posavje hills (highest peak: Kum, $1211 \mathrm{~m})$. Immediately to the south is Ljubljansko Marshes (Šajn et al., 2011), a drained ancient moor that was frequently a lake during the ice ages (Fig. 1b) (Pak, 1992).

The air quality of Ljubljana is affected by a combination of local and remote influences, the relative contributions of which are dictated by prevailing meteorology. The geographic location of Slovenia (Fig. 1a) is such that remote influences on air quality, when they occur, are mainly a result of pollution transport from northern Africa (Kallos et al., 2006), from the North Atlantic Ocean, and across Italy from the Mediterranean Sea (He et al., 2018), the northern Balkan Peninsula, or eastern Europe (Poberžnik and Štrumbelj, 2016).

Drag associated with the complex topography of the surrounding region retards synoptic-scale winds, resulting in a mean near-surface annual wind speed of only $1.3 \mathrm{~m} \mathrm{~s}^{-1}$. Extended periods of anticyclonic conditions (low-gradient winds and subsidence) are also common for the region. Combined with the unique concave shape of the subalpine Ljubljana basin (Rakovec et al., 2002), this results in comparatively calm conditions in the colder months, with frequent foggy days and persistent temperature inversions $\left(120 \mathrm{~d} \mathrm{y}^{-1}\right)$, favoring the buildup of locally sourced emissions.

\subsection{Measurement methods}

Atmospheric radon measurements were made for 1 year (14 December 2016 to 30 November 2017) at the Ljubljana Bežigrad $(\mathrm{LjB})$ automatic weather station in the central part of the city $\left(46^{\circ} 07^{\prime} \mathrm{N}, 14^{\circ} 52^{\prime} \mathrm{E}\right.$; Fig. 1c), and are ongoing. The measurements were conducted using an AlphaGUARD PQ2000 PRO (Bertin Instruments) ionization chamber operating in diffusion mode with a $1 \mathrm{~h}$ integration time. The instrument was mounted $1.5 \mathrm{~m}$ above ground level (m a.g.l.), within a Stevenson Screen instrument shelter. Setup in this way more than $95 \%$ of the observed radon concentrations represent the isotope ${ }^{222} \mathrm{Rn}$ (Kochowska et al., 2009). Consequently, to a good approximation contributions from the isotopes ${ }^{220} \mathrm{Rn}$ (thoron) and ${ }^{219} \mathrm{Rn}$ (actinon) can be ignored. The AlphaGUARD has a lower limit of detection (LLD) of around $2 \mathrm{~Bq} \mathrm{~m}^{-3}$. Over the year only $1 \%$ of observed radon concentrations were at or below this limit, which justifies the continued use of the AlphaGUARD at this site as a tool for air quality assessment.
The LjB weather station, operated by the National Meteorological Service at the Environmental Agency of the Republic of Slovenia (ARSO), also has a comprehensive suite of meteorological sensors. The following parameters, recorded at $2 \mathrm{~m}$ a.g.l. and aggregated to hourly temporal resolution, were used in this study: air temperature $\left({ }^{\circ} \mathrm{C}\right)$, relative humidity $(\%)$, wind speed $\left(\mathrm{m} \mathrm{s}^{-1}\right)$, wind direction $\left(^{\circ}\right)$, and precipitation $\left(\mathrm{mm} \mathrm{h}^{-1}\right)$ as well as the standard air quality parameter $\mathrm{PM}_{10}\left(\mu \mathrm{g} \mathrm{m}^{-3}\right)$ (ARSO, 2017). To supplement these observations, total cloud cover (\%) was obtained from the Global Data Assimilation System (GDAS) model of NOAA ARL (National Oceanic and Atmospheric Administration Air Resources Laboratory).

In addition to the $\mathrm{LjB}$ air temperature measurements near the bottom of the Ljubljana basin (299 ma.s.1.), ARSO air temperature observations were also retrieved from a number of weather stations on the sidewalls of the basin at a range of elevations from 268 to $1742 \mathrm{~m}$. A full list of station names, abbreviations, and elevations is provided in Table 1, and their locations relative to $\mathrm{LjB}$ are shown in Fig. 1c. To facilitate subsequent analyses, each station was assigned an elevation category (low, medium, or high) according to its elevation relative to the bottom of the basin (Table 1).

The statistical analyses for this study were performed using the ggplot2 (Wickham, 2009) and imputeTS (Moritz, 2017) packages under R 3.3.1 (R Development Core Team, 2008). All reported times are local (local time is UTC+1) and the Northern Hemisphere seasonal convention has been adopted (i.e., winter: December-February; spring: March-May; summer: June-August; autumn: SeptemberNovember).

\subsection{Identifying persistent temperature inversion events}

\subsubsection{The radon-based method (RBM)}

Our method for identifying PTI events is based on continuous, near-surface, single-height observations of atmospheric radon concentrations. The principle of the method is outlined in the following two steps: (i) minimize or separate contributions to the observed radon variability occurring at the four main timescales (sub-diurnal, diurnal, synoptic, and greaterthan synoptic), and then (ii) compare the relative magnitudes of variability contributed by the diurnal and synoptic timescales. Since the separation and comparison of different timescale contributions to radon concentration variability is performed separately for each season and year, changes in mean rates of radon emission between seasons or years do not adversely affect the efficacy of the technique.

Although the performance of the method is seasonally independent, the greatest number of PTI events in the SAB occurs in winter, so here we focus only on winter observations for the purpose of demonstrating the method. The processes involved in minimizing or separating contributing timescales to the observed radon time series in order to isolate the syn- 


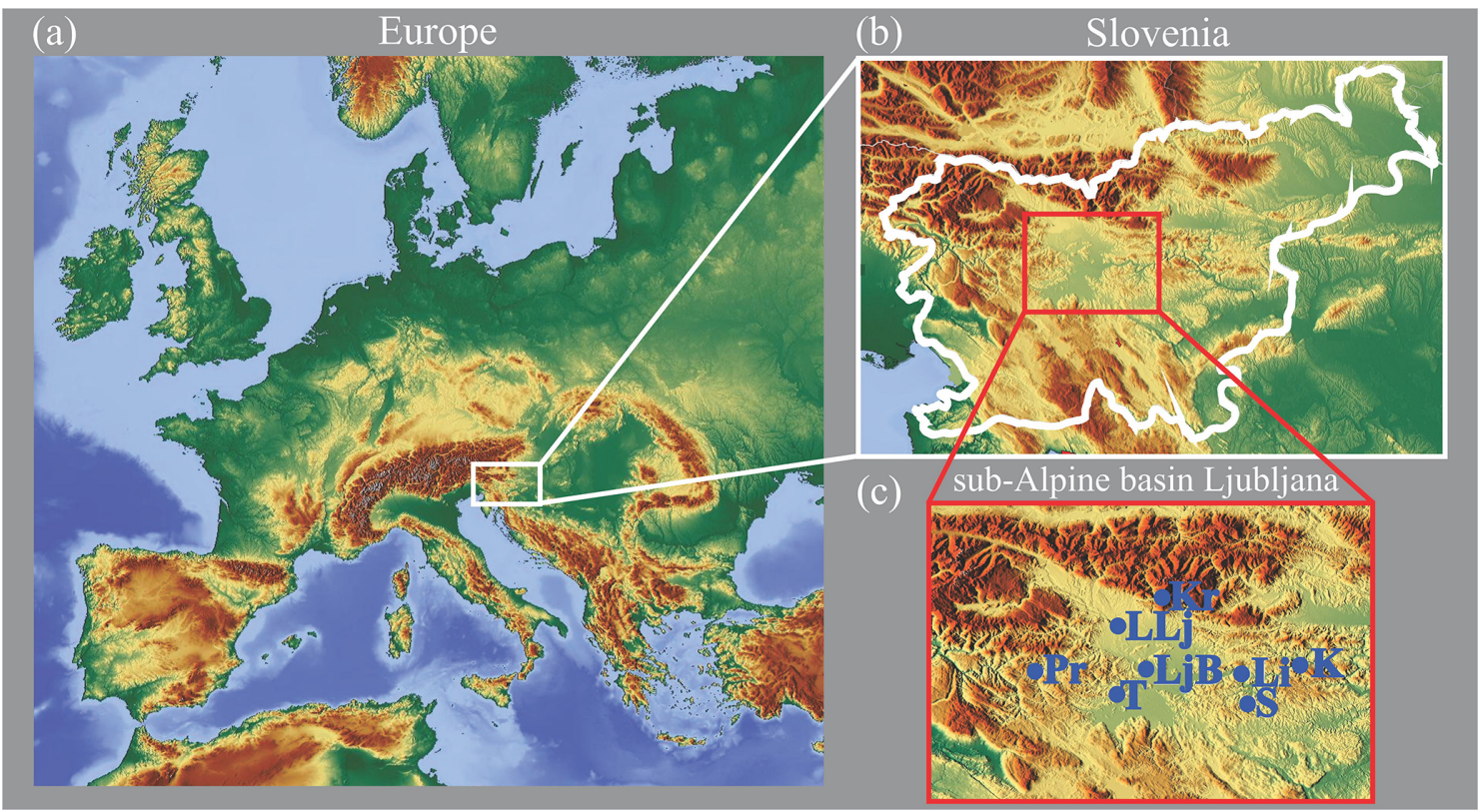

Figure 1. (a) Location of Slovenia within Europe, (b) topographic map of Slovenia with the location of Ljubljana indicated, and (c) topographic map of the Ljubljana basin, with the locations of automatic weather stations indicated. Basemap source: (C) https://www. openstreetmap.org/copyright, last access: 11 August 2019.

Table 1. Ground-based automatic weather station name, abbreviation, position, elevation, and elevation category.

\begin{tabular}{llllll}
\hline Station name & Acronym & Latitude $\left({ }^{\circ} \mathrm{N}\right)$ & Longitude $\left({ }^{\circ} \mathrm{E}\right)$ & Elevation $(\mathrm{m})$ & Elevation category \\
\hline Litija & $\mathrm{Li}$ & $46^{\circ} 06^{\prime}$ & $14^{\circ} 81^{\prime}$ & $268 \mathrm{~m}$ & low \\
Ljubljana-Bežigrad & $\mathrm{LjB}$ & $46^{\circ} 07^{\prime}$ & $14^{\circ} 52^{\prime}$ & $299 \mathrm{~m}$ & low \\
Letališče Jožeta Pučnika Ljubljana & $\mathrm{LLj}$ & $46^{\circ} 21^{\prime}$ & $14^{\circ} 47^{\prime}$ & $364 \mathrm{~m}$ & low \\
Sevno & $\mathrm{S}$ & $45^{\circ} 98^{\prime}$ & $14^{\circ} 92^{\prime}$ & $556 \mathrm{~m}$ & medium \\
Topol & $\mathrm{T}$ & $46^{\circ} 09^{\prime}$ & $14^{\circ} 37^{\prime}$ & $695 \mathrm{~m}$ & medium \\
Pasja Ravan & $\mathrm{PR}$ & $46^{\circ} 09^{\prime}$ & $14^{\circ} 22^{\prime}$ & $1019 \mathrm{~m}$ & high \\
Kum & $\mathrm{K}$ & $46^{\circ} 08^{\prime}$ & $15^{\circ} 07^{\prime}$ & $1211 \mathrm{~m}$ & high \\
Krvavec & $\mathrm{Kr}$ & $46^{\circ} 29^{\prime}$ & $14^{\circ} 53^{\prime}$ & $1742 \mathrm{~m}$ & high \\
\hline
\end{tabular}

optic timescale contributions for further analysis (i.e., Step 1) are outlined below.

1. Minimizing instrument uncertainty and sub-diurnal radon variability. Since afternoon radon concentrations can be close to the instruments' detection limit (even in winter), measurement uncertainty cannot be neglected. Furthermore, as outlined in Sect. 1 numerous factors contribute to natural variability in observed radon concentrations at sub-diurnal timescales. To minimize the impact of the above contributions on our estimation of diurnal minimum radon concentrations, we started by performing a $3 \mathrm{~h}$ running mean smoothing on the observed radon concentrations (Fig. 3a, black line, $\left.C_{\text {Rn-observed }}\right)$.

2. Characterization of the synoptic variability ("fetch ef$f e c t$ "). Mean summer and winter diurnal radon cycles at $\mathrm{LjB}$ are shown in Fig. 2a. As detailed in Sect. 1, these cycles are characterized by peak concentrations near sunrise, when near-surface mixing is usually suppressed, and minimum values in the midafternoon, when the ABL is deep (typically $\geq 1 \mathrm{~km}$ ) and uniformly mixed. Depending on season (specifically, the duration and intensity of solar radiation), the timing and duration of the diurnal maximum and minimum concentration periods may change by several hours (Fig. 2a). For a given season, afternoon minimum radon concentrations are primarily influenced by the combined radon emissions along the air masses' recent (two to three radon half-lives) fetch, which changes with the passage of synoptic weather systems. Diurnal variability (driven by changes in mixing depth and the local radon flux) is superimposed on top of this fetch-driven radon variability. As an economical alternative to vertical radon gradient 
measurements (which require multiple research-grade detectors), the fetch-related influence (synoptic contribution) to radon concentrations observed at a single height can be approximated by linearly interpolating between successive afternoon minimum values (Chambers et al., 2015; Podstawczyńska and Chambers, 2018). For the purpose of this investigation we derived the daily minimum radon concentrations over the year of observations by identifying the minimum smoothed concentration each afternoon between 14:00 and 19:00 LT. An example of this linearly interpolated approximation of the air mass fetch contribution to the $\mathrm{LjB}$ radon concentrations is shown in Fig. 3a (light blue line, $C_{\mathrm{Rn} \text {-advected }}$ ). It should be noted that the assumptions upon which this fetch-effect approximation is based are invalid under severe weather conditions (e.g., during the passage of strong frontal systems, or rapid changes from terrestrial to oceanic fetch).

3. Isolation of synoptic contribution from longer timescale radon contributions. Variability on greater than synoptic timescales was evident in the radon time series, which needed to be minimized prior to attempting to identify PTI events. The first step was to characterize typical synoptic timescale variability at $\mathrm{LjB}$. We did this by performing a spectral analysis of the hourly $\mathrm{LjB}$ atmospheric pressure observations for each season (Fig. 2b; winter and summer examples). Throughout winter and autumn our analysis indicated a synoptic timescale of 5 to $8 \mathrm{~d}$, whereas in spring and summer the synoptic timescale was typically 6 to $7 \mathrm{~d}$. We then calculated a running-minimum radon concentration using a window derived from the spectral analysis of atmospheric pressure $(7 \mathrm{~d}$ window for all seasons). Lastly, this running-minimum concentration (Fig. 3a; blue line, $\left.C_{\text {Rn-subtracted }}\right)$ was subtracted from the $C_{\mathrm{Rn} \text {-advected }}$ (fetch effect) derived in (2) above, in order to isolate the synoptic timescale contributions to the radon observations (Fig. $3 \mathrm{~b}$; red line, $C_{\mathrm{Rn} \text {-synoptic }}$ ). The $\mu \pm \sigma$ of the subtracted radon contribution was $4.2 \pm 2.1$, $3.1 \pm 0.5,3.8 \pm 0.7$, and $4.8 \pm 1.3 \mathrm{~Bq} \mathrm{~m}^{-3}$, for winter, spring, summer, and autumn, respectively.

Having isolated the synoptic-scale contribution to the observed radon time series, the next steps to develop the PTI identification tool were to (i) identify periods when synoptic variability dominates diurnal variability, and (ii) decide on a minimum length of time that this needs to occur for the event to be considered a PTI.

The diurnal (mixing-related) contribution to the $\mathrm{LjB}$ radon time series was obtained by subtracting the advected signal from the measured radon concentrations (see Fig. 3a). For the purpose of this study we chose the seasonal standard deviation $(+\sigma)$ of the diurnal radon contribution as a measure of the significance of diurnal variability each season. For our winter example, in Fig. $3 \mathrm{~b}$ we plotted the isolated synoptic radon signal $\left(C_{\mathrm{Rn} \text {-synoptic }}\right)$ and the standard deviation of the winter diurnal radon signal $\left(+\sigma\left(C_{\mathrm{Rn} \text {-diurnal }}\right) \mathrm{W}\right)$. Numerous cases were evident when accumulation of radon due to synoptic processes $\left(C_{\mathrm{Rn} \text {-synoptic }}\right)$ exceeded $+\sigma\left(C_{\mathrm{Rn} \text {-diurnal }}\right) \mathrm{W}$. At such times, synoptic controls on the near-surface radon observations are more significant than diurnal controls. The final step is to set a duration threshold on these exceedances for an event to be classified as a PTI.

We consider a persistent temperature inversion event to have occurred when the synoptic contribution to the radon signal exceeds the standard deviation of the diurnal contribution for that season for a period of at least $48 \mathrm{~h}$ :

$\left(C_{\mathrm{Rn} \text {-synoptic }}\right)>+\sigma\left(C_{\mathrm{Rn} \text {-diurnal }}\right)_{\text {season }}$ for $\geq 48 \mathrm{~h}$.

Although only a winter example is presented in Figure 3b, the same approach was used for all seasons.

\subsubsection{The pseudo-vertical temperature gradient method (TGM)}

If distributed ground-based air temperature measurements are available over a wide range of representative elevations within a basin or valley, it is possible to identify PTI events by analyzing pseudo-vertical temperature gradients between stations with significantly different elevations. This method, described by Largeron and Staquet (2016a), relies upon two key assumptions: (1) horizontal homogeneity of air temperature between stations of similar elevations and (2) the existence of significant vertical changes in air temperature between stations at different elevations. The validity of these assumptions can be assessed by calculating correlations between stations within designated elevation groups, and between stations across designated elevation groups. If the assumptions hold, temperature gradients between stations within the designated elevation groups can be calculated, and a threshold value determined to identify PTI events.

As detailed in Table 1, in the case of the Ljubljana basin, air temperature observations were available from eight automatic weather stations representative of three different elevation categories (low $\sim 310 \mathrm{~m}$, medium $\sim 630 \mathrm{~m}$, and high $\sim 1320 \mathrm{~m}$ ) for detecting PTI events. Firstly, all hourly temperature observations from the eight stations over the December 2016 to November 2017 period were separated by season. Next, seasonal correlation coefficients between each of the eight stations were calculated separately (Table 2). Air temperatures from the three low-elevation stations $(\mathrm{Li}, \mathrm{LjB}$, and $\mathrm{LLj}$ ) were strongly correlated for all seasons, despite a spatial separation of up to $\sim 60 \mathrm{~km}$ (Fig. 1c). Likewise, air temperatures of the two medium-elevation stations ( $\mathrm{S}$ and $\mathrm{T}$ ) were strongly correlated for all seasons. In the case of the high-elevation stations (PR, K, and $\mathrm{Kr}$ ), however, only moderate correlation coefficients were obtained (Table 2), indicating a degree of non-homogeneity of the horizontal air temperature field near the top of the basin. 

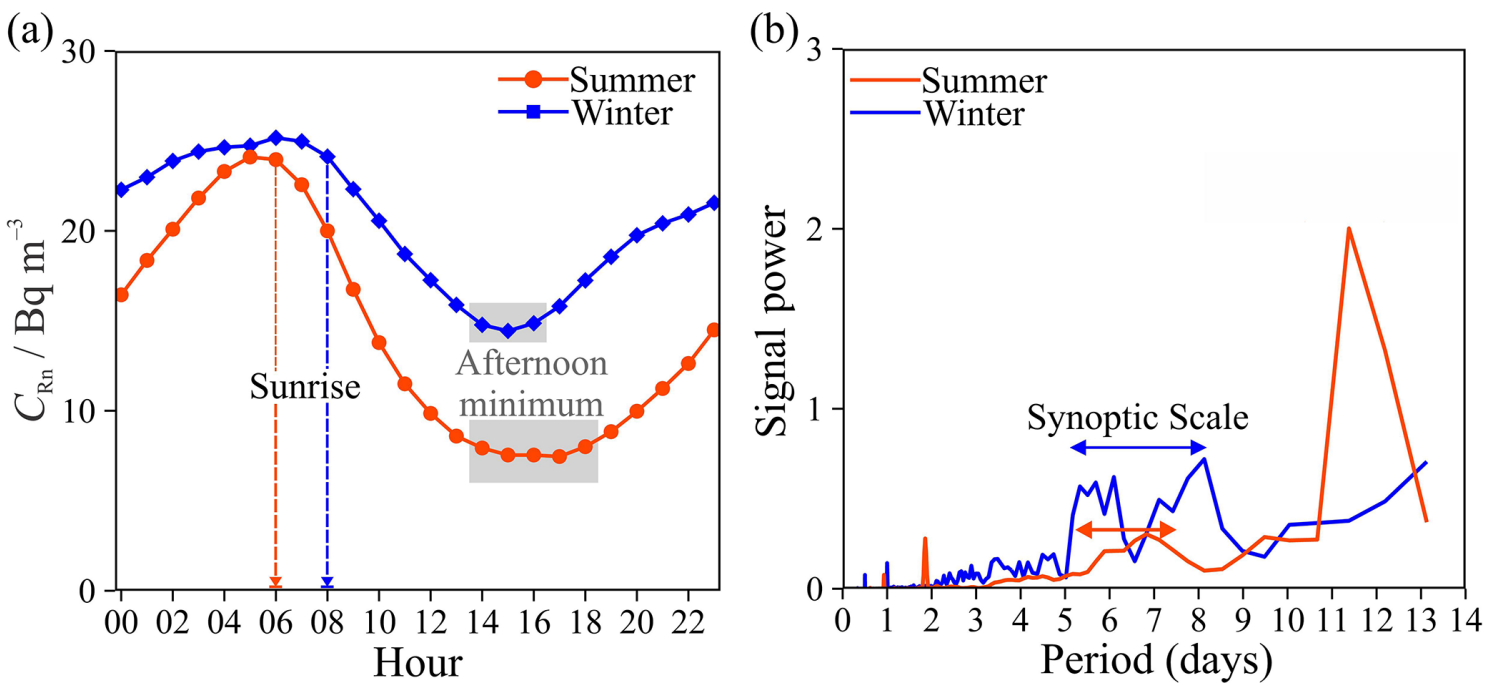

Figure 2. (a) Summer and winter diurnal composite hourly radon concentration and (b) spectral analysis of the LjB hourly atmospheric pressure data for summer and winter.

Table 2. Air temperature correlation coefficients between each of the eight ground-based automatic weather stations in spring, summer, autumn, and winter.

\begin{tabular}{|c|c|c|c|c|c|c|c|c|c|c|c|c|c|c|c|c|c|}
\hline \multicolumn{9}{|c|}{ Winter } & \multicolumn{9}{|c|}{ Spring } \\
\hline & $\mathrm{Li}$ & $\mathrm{LjB}$ & $\mathrm{LLj}$ & $\mathrm{S}$ & $\mathrm{T}$ & PR & $\mathrm{K}$ & $\mathrm{Kr}$ & & $\mathrm{Li}$ & $\mathrm{LjB}$ & LLj & $S$ & $\mathrm{~T}$ & PR & $\mathrm{K}$ & $\mathrm{Kr}$ \\
\hline $\mathrm{Li}$ & 1 & 0.96 & 0.94 & 0.81 & 0.74 & 0.59 & 0.47 & 0.27 & $\mathrm{Li}$ & 1 & 0.97 & 0.97 & 0.89 & 0.87 & 0.87 & 0.83 & 0.74 \\
\hline $\mathrm{LjB}$ & & 1 & 0.95 & 0.84 & 0.78 & 0.59 & 0.47 & 0.26 & $\mathrm{LjB}$ & & 1 & 0.96 & 0.91 & 0.91 & 0.80 & 0.86 & 0.80 \\
\hline LLj & & & 1 & 0.80 & 0.75 & 0.59 & 0.46 & 0.24 & $\mathrm{LLj}$ & & & 1 & 0.88 & 0.87 & 0.88 & 0.83 & 0.80 \\
\hline S & & & & 1 & 0.96 & 0.80 & 0.69 & 0.46 & $\mathrm{~S}$ & & & & 1 & 0.97 & 0.96 & 0.96 & 0.90 \\
\hline $\mathrm{T}$ & & & & & 1 & 0.85 & 0.74 & 0.52 & $\mathrm{~T}$ & & & & & 1 & 0.98 & 0.96 & 0.92 \\
\hline PR & & & & & & 1 & 0.84 & 0.75 & PR & & & & & & 1 & 0.76 & 0.71 \\
\hline $\mathrm{K}$ & & & & & & & 1 & 0.75 & $\mathrm{~K}$ & & & & & & & 1 & 0.94 \\
\hline $\mathrm{Kr}$ & & & & & & & & 1 & $\mathrm{Kr}$ & & & & & & & & 1 \\
\hline \multicolumn{9}{|c|}{ Summer } & \multicolumn{9}{|c|}{ Autumn } \\
\hline & $\mathrm{Li}$ & $\mathrm{LjB}$ & $\mathrm{LLj}$ & $\mathrm{S}$ & $\mathrm{T}$ & PR & $\mathrm{K}$ & $\mathrm{Kr}$ & & $\mathrm{Li}$ & $\mathrm{LjB}$ & LLj & $\mathrm{S}$ & $\mathrm{T}$ & PR & $\mathrm{K}$ & $\mathrm{Kr}$ \\
\hline $\mathrm{Li}$ & 1 & 0.95 & 0.97 & 0.87 & 0.85 & 0.85 & 0.81 & 0.66 & $\mathrm{Li}$ & 1 & 0.97 & 0.95 & 0.88 & 0.85 & 0.82 & 0.80 & 0.70 \\
\hline $\mathrm{LjB}$ & & 1 & 0.96 & 0.91 & 0.91 & 0.98 & 0.83 & 0.72 & $\mathrm{LjB}$ & & 1 & 0.94 & 0.90 & 0.88 & 0.84 & 0.81 & 0.72 \\
\hline LLj & & & 1 & 0.89 & 0.89 & 0.98 & 0.83 & 0.68 & $\mathrm{LLj}$ & & & 1 & 0.85 & 0.83 & 0.82 & 0.78 & 0.70 \\
\hline S & & & & 1 & 0.97 & 0.96 & 0.96 & 0.90 & $S$ & & & & 1 & 0.98 & 0.96 & 0.94 & 0.85 \\
\hline $\mathrm{T}$ & & & & & 1 & 0.98 & 0.96 & 0.92 & $\mathrm{~T}$ & & & & & 1 & 0.97 & 0.95 & 0.86 \\
\hline PR & & & & & & 1 & 0.76 & 0.71 & PR & & & & & & 1 & 0.77 & 0.78 \\
\hline $\mathrm{K}$ & & & & & & & 1 & 0.94 & $\mathrm{~K}$ & & & & & & & 1 & 0.73 \\
\hline $\mathrm{Kr}$ & & & & & & & & 1 & $\mathrm{Kr}$ & & & & & & & & 1 \\
\hline
\end{tabular}

Vertical temperature gradients between the low- and medium-elevation stations and the medium- and highelevation stations were not as distinct in spring, summer, or autumn as they were in winter, as indicated by strong correlation coefficients between temperatures from those elevations (Table 2). Thus, according to Whiteman et al. (2004), the actual vertical temperature profile of the basin's atmosphere can only be suitably approximated by pseudo-vertical temperature gradient measurements from the ground-based stations over the whole year at night, when convective mixing is not active. Only in the colder months (winter and some of autumn; under low-gradient wind conditions) can the pseudo-vertical temperature gradient be used effectively over the whole diurnal cycle.

Making the assumption of year-round horizontal homogeneity of the temperature field (Largeron and Staquet, 

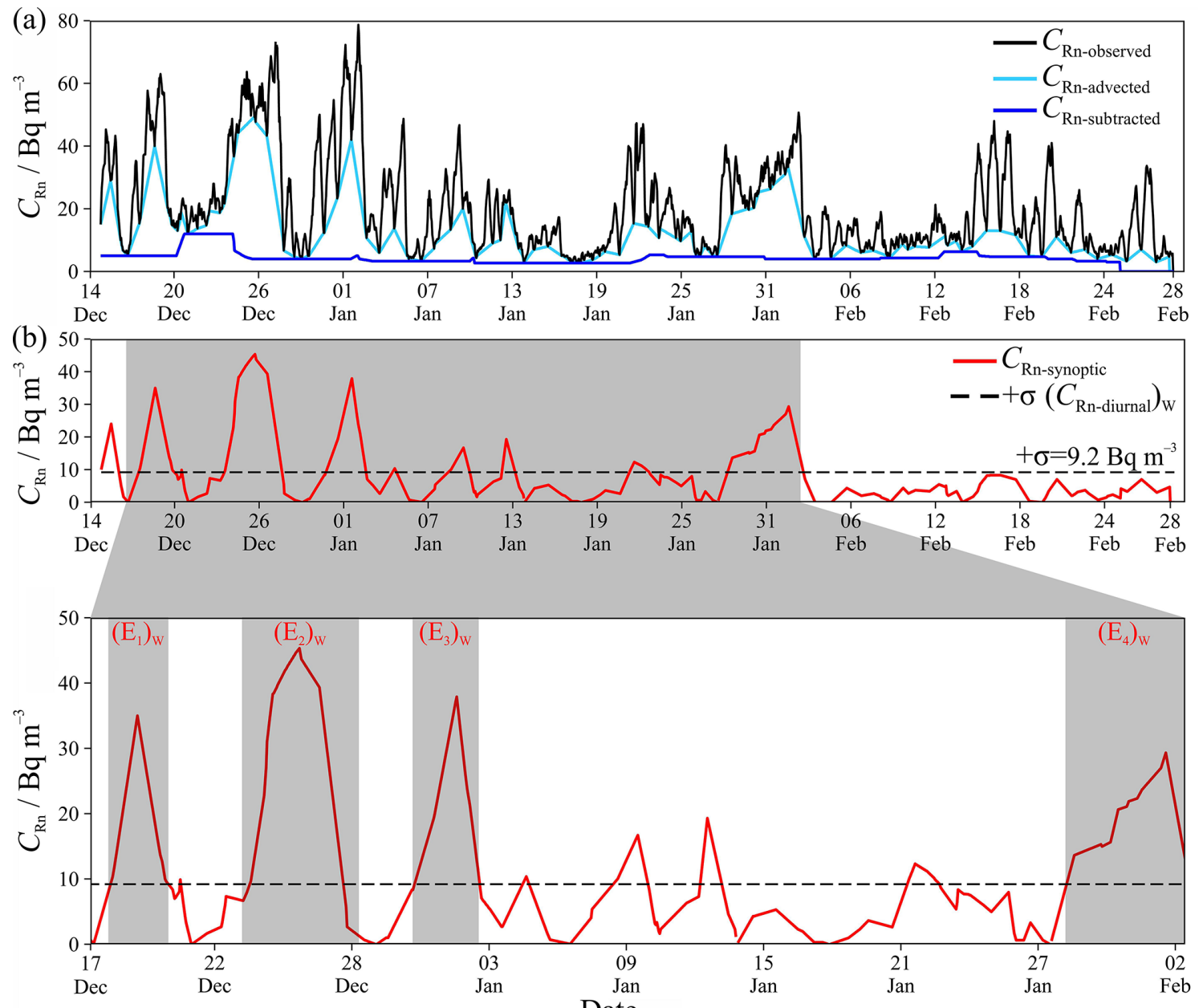

Figure 3. (a) Hourly mean observed radon concentrations, the advected radon contribution with subtracted radon indicated, and (b) isolated synoptic timescale radon contribution in winter with the standard deviation $(+\sigma)$ of the diurnal contribution indicated. Four persistent temperature inversion events $\left(E_{i}\right)_{\mathrm{W}}$ detected by the RBM are shown in the shaded area and enlarged in the breakout panel beneath; see text in Sect. 2.3.1 for details.

2016a), a relative measure of the degree of stability of the ABL can be made by calculating the vertical temperature gradient between stations of different elevation categories (e.g., high-medium, high-low, or medium-low), $(\Delta T / \Delta z)_{i}$, where the index $i$ refers to any pair of stations. To this end, following Largeron and Staquet (2016a), we calculated pseudo-vertical temperature gradients for four station pairs. Of the 21 possible gradient combinations we sought to avoid medium-high gradient pairs (since the high stations were not internally well correlated), and avoided the use of station $\mathrm{S}$ in the medium height category due to its comparatively high correlation with temperatures of the low stations. Other combinations were chosen to minimize spatial separation. The gradient pairs chosen for this study were as follows:

i. $\mathrm{Li}$ and $\mathrm{K},(\Delta T / \Delta z)_{1}, 29 \mathrm{~km}$ apart, $\Delta z=943 \mathrm{~m}$;

ii. $\mathrm{LjB}$ and $\mathrm{T},(\Delta T / \Delta z)_{2}, 19 \mathrm{~km}$ apart, $\Delta z=396 \mathrm{~m}$; iii. $\mathrm{LjB}$ and $\mathrm{PR},(\Delta T / \Delta z)_{3}, 35 \mathrm{~km}$ apart, $\Delta z=720 \mathrm{~m}$;

iv. $\mathrm{LLj}$ and $\mathrm{Kr},(\Delta T / \Delta z)_{4}, 23 \mathrm{~km}$ apart, $\Delta z=1378 \mathrm{~m}$.

Following Largeron and Staquet (2016a) we derived our basin stability measure (the pseudo-vertical temperature gradient) from the average of the four separate gradients:

$\frac{\Delta T}{\Delta z}(t)=\frac{1}{4} \sum_{i=1}^{4}\left(\frac{\Delta T}{\Delta z}\right)_{i}(t)$.

We note, however, that $\Delta T / \Delta z$ and the individual gradients $(\Delta T / \Delta z)_{i}$ were typically very similar:

$\frac{\Delta T}{\Delta z}(t) \approx\left(\frac{\Delta T}{\Delta z}\right)_{i}(t)$ for $i=1 \ldots 4$.

In order to avoid the detection of successive strong nocturnal-only temperature inversions and isolate persistent 


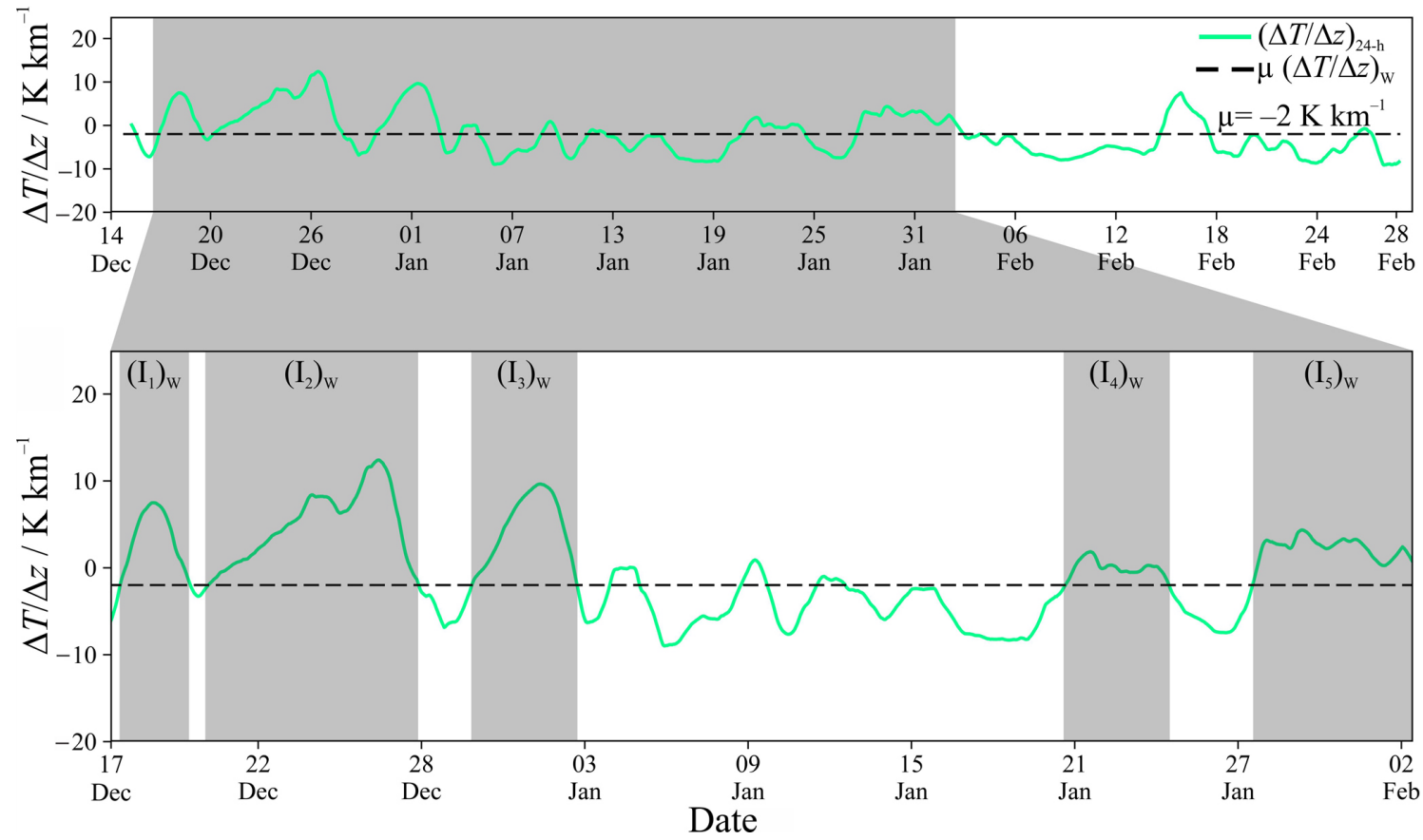

Figure 4. The $24 \mathrm{~h}$ running mean pseudo-vertical temperature gradient in winter. Five persistent temperature inversion events $\left(I_{i}\right)_{\mathrm{W}}$ detected by the TGM are shown in the shaded area and enlarged in the breakout panel beneath; see text in Sect. 2.3.2 for details.

temperature inversion events, we applied a $24 \mathrm{~h}$ running mean smoothing to the pseudo-vertical temperature gradient $\left((\Delta T / \Delta z)_{24 \mathrm{~h}}\right)$. Lastly, we calculated seasonal average $(\mu)$ values of $\Delta T / \Delta z$ to use as our seasonal thresholds for PTI event identification, a slight deviation from the approach of Largeron and Staquet (2016a), which used the cold season average (November-December).

A persistent temperature inversion event is considered to have occurred when the $(\Delta T / \Delta z)_{24} \mathrm{~h}$ value exceeds the seasonal average value for $\geq 48 \mathrm{~h}$ :

$(\Delta T / \Delta z)_{24 \mathrm{~h}}>\mu(\Delta T / \Delta z)_{\text {season }}$ for $\geq 48 \mathrm{~h}$.

As an example of this technique we present the winter event selection results in Fig. 4. The same approach was used for all seasons.

\section{Results and discussion}

\subsection{Data overview}

The time series of hourly average radon concentration at $\mathrm{LjB}$ revealed a seasonal cycle, characterized by a winter maximum and summer minimum (Fig. 5a). When monthly averages of the separated synoptic- and diurnal-scale contributions to the radon observations are considered (Fig. 5c) it is clear that the seasonal cycle is mainly controlled by synoptic factors (changes in air mass fetch or time over land).

From October through December monthly mean wind speeds were typically low (Fig. 5c), associated with fre- quent synoptic stagnation events. These periods resulted in higher radon concentrations (long time over land). In January and February, even though monthly average wind speeds increased, recent air mass fetch was predominantly continental, as indicated by dominant NE-E winds in seasonal wind roses (not shown), resulting in moderate monthly mean radon concentrations. The lowest synoptic contributions to observed radon concentrations occurred in spring and summer. During these times the mean monthly wind speeds were higher (strong mixing), and wind directions were often from the southwest, in the direction of the Gulf of Venice and Adriatic Sea, so terrestrial fetch for air masses was limited. In a few specific cases (e.g., April and August), intense rainfall events appeared to be associated with a reduction in radon concentrations, likely attributable to short-term reductions in the radon flux (Fig. 5b).

From March through September in Fig. 5a the variability in radon concentration appears to be of considerably higher frequency than from October through February. This is further evidence of a change in dominant influences from diurnal to synoptic timescales, associated with changing day length and intensity of solar radiation within the Ljubljana basin. The period of greater synoptic influence (reduced diurnal radon variability) corresponds well with times when mean daily temperatures were close to or below $0^{\circ} \mathrm{C}$, when soil freezing was likely (Fig. 5a and b). 

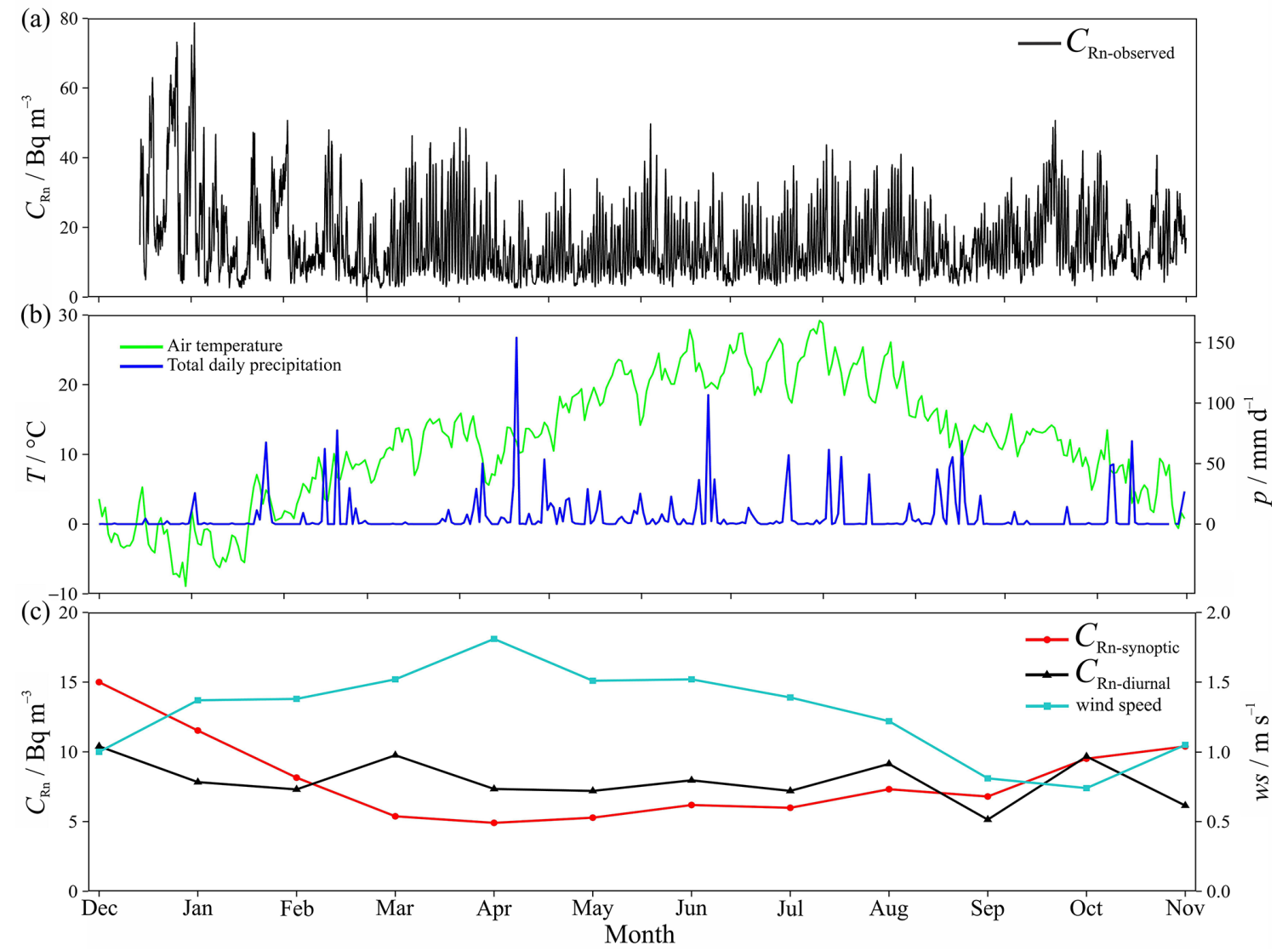

Figure 5. A total of 1 year (December 2016 to November 2017) of (a) hourly mean radon concentration, (b) hourly mean air temperature and total daily precipitation, and (c) monthly mean of synoptic radon, diurnal mixing of radon, and wind speed.

Table 3. Persistent temperature inversion events $\left(E_{i}\right)$ by season (winter, W; spring, Sp; summer, S; autumn, A) detected by the radon-based method (RBM), including time period and duration.

\begin{tabular}{lll}
\hline Event & Persistent inversion period & Duration \\
\hline$\left(E_{1}\right)_{\mathrm{W}}$ & $17 / 12 / 2016-19 / 12 / 2016$ & $59 \mathrm{~h}(2.5 \mathrm{~d})$ \\
$\left(E_{2}\right)_{\mathrm{W}}$ & $23 / 12 / 2016-27 / 12 / 2016$ & $101 \mathrm{~h}(4.2 \mathrm{~d})$ \\
$\left(E_{3}\right)_{\mathrm{W}}$ & $30 / 12 / 2016-02 / 01 / 2017$ & $72 \mathrm{~h}(3 \mathrm{~d})$ \\
$\left(E_{4}\right)_{\mathrm{W}}$ & $28 / 01 / 2017-02 / 02 / 2017$ & $131 \mathrm{~h}(5.5 \mathrm{~d})$ \\
$\left(E_{1}\right)_{\mathrm{A}}$ & $14 / 10 / 2017-18 / 10 / 2017$ & $96 \mathrm{~h}(4 \mathrm{~d})$ \\
$\left(E_{2}\right)_{\mathrm{A}}$ & $19 / 11 / 2017-21 / 11 / 2017$ & $48 \mathrm{~h}(2 \mathrm{~d})$ \\
\hline
\end{tabular}

\subsection{Radon-based PTI event selection (RBM)}

The radon-based method (RBM) identified six PTI events in the basin over the whole year of measurements. Four events were detected in winter (hereafter $\left.\left(E_{i}\right)_{\mathrm{W}}\right)$ and two in autumn $\left(\left(E_{i}\right)_{\mathrm{A}}\right)$. Dates, times, and durations of these events are summarized numerically in Table 3 and graphically in Fig. 3b (winter) and Fig. 6b (autumn). The RBM detected no PTI events in spring and summer (see Figs. $7 \mathrm{~b}$ and $8 \mathrm{~b}$ ).
According to the RBM approximately $20 \%$ of winter experienced persistent strongly stable conditions, associated with anticyclonic synoptic conditions in the basin and surrounding regions. By contrast, the RBM classified only $7 \%$ of autumn as PTI events. Events $\left(E_{1}\right)_{\mathrm{A}}$ and $\left(E_{2}\right)_{\mathrm{A}}$ lasted 4 and $2 \mathrm{~d}$, respectively, and both occurred in the second half of autumn.

\subsection{Pseudo-vertical temperature gradient PTI event selection (TGM)}

A total of 17 PTI events were detected throughout the measurement year by the TGM. Dates, times, and duration of these events are summarized in Table 4. Five events were detected in winter (hereafter $\left.\left(I_{i}\right)_{\mathrm{W}}\right)$, three in spring $\left(\left(I_{i}\right)_{\mathrm{Sp}}\right)$, two in summer $\left(\left(I_{i}\right)_{\mathrm{S}}\right)$, and seven in autumn $\left(\left(I_{i}\right)_{\mathrm{A}}\right)$, as illustrated in Figs. 4, 9, 10, and 11.

Approximately $30 \%$ of winter days experienced persistently stable conditions according to the TGM. All of the TGM-classified events lasted from 3 to $8 \mathrm{~d}$ and were associated with strong inversion conditions (based on the mean vertical temperature gradients) with the exception of $\left(I_{4}\right)_{\mathrm{W}}$, which was of lower intensity (Fig. 4). The highest number 

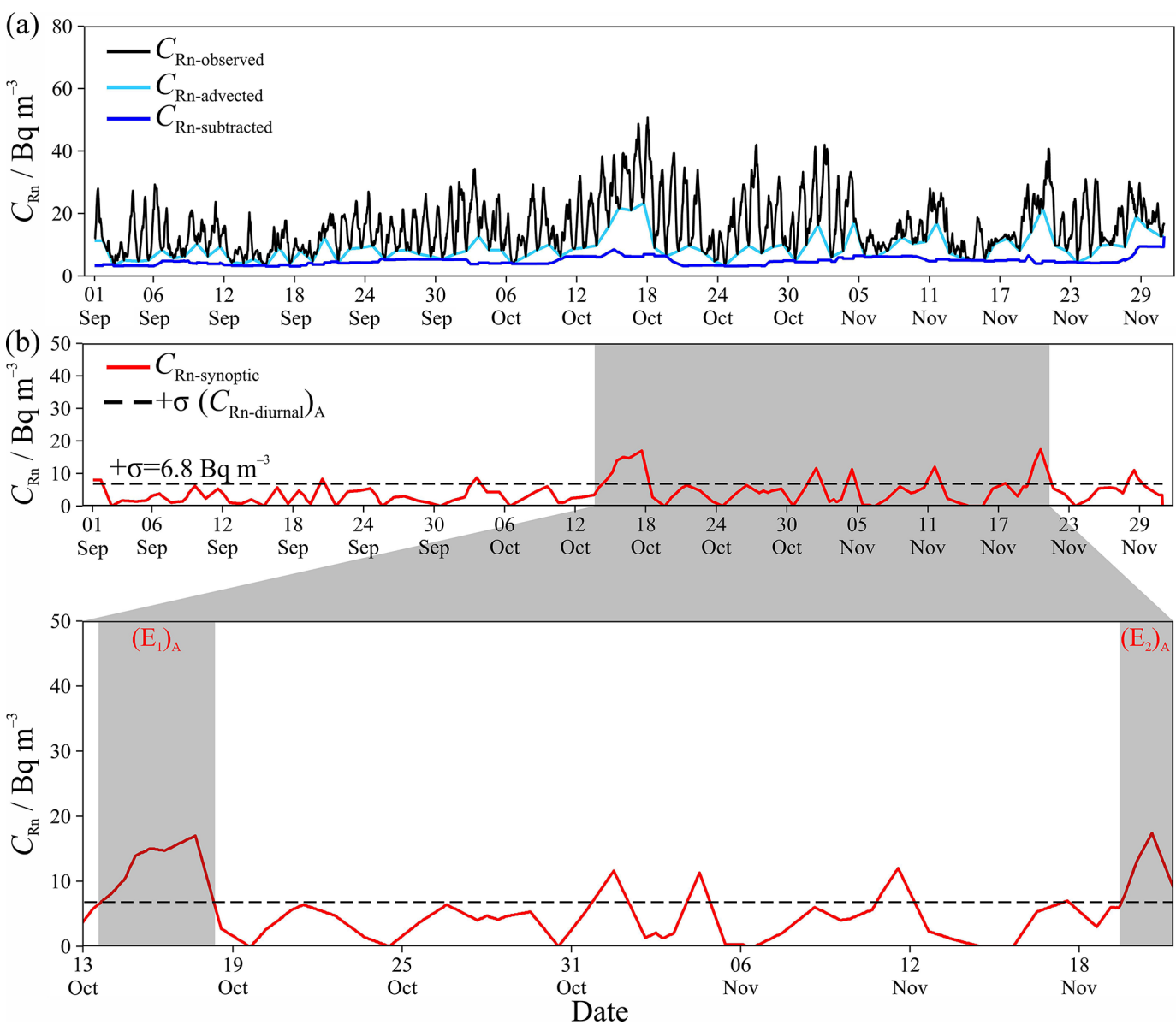

Figure 6. (a) Hourly mean observed radon concentrations, the advected radon contribution with subtracted radon indicated, and (b) isolated synoptic timescale radon contribution in autumn with the standard deviation $(+\sigma)$ of the diurnal contribution indicated. Two persistent temperature inversion events $\left(E_{i}\right)_{\mathrm{A}}$ detected by the RBM are shown in the shaded area and enlarged in the breakout panel beneath; see text in Sect. 2.3.1 for details.

of PTI events identified by the TGM was in autumn (Fig. 9). Around $32 \%$ of this season was classified as PTI conditions. The identified $\left(I_{i}\right)_{\mathrm{A}}$ had durations of 2 to $12 \mathrm{~d}$, with $\left(I_{1}\right)_{\mathrm{A}}$, $\left(I_{2}\right)_{\mathrm{A}}$, and $\left(I_{7}\right)_{\mathrm{A}}$ being the shortest and with the least intense stability. The longest-lasting event with the strongest stability was $\left(I_{3}\right)_{\mathrm{A}}$.

In contrast to the RBM, the TGM also identified PTI events in spring (22\%) and summer (26\%) (Figs. 10 and 11).

\subsection{Comparison of the radon-based and temperature gradient methods}

Diurnal composites, based on hourly means, of air temperature, relative humidity, cloud cover, wind speed, wind direction, and precipitation for all conditions (winter mean) and for typical PTI event days in winter selected by RBM and TGM are shown in Fig. 12. As evident, winter RBM PTI days were mainly associated with modest diurnal temperature amplitudes $\left(\sim 5^{\circ} \mathrm{C}\right.$ on average $)$, with morning minimums mostly between 0 and $-4^{\circ} \mathrm{C}$ (Fig. 12a). The diurnal ampli- tude of relative humidity was $\sim 15 \%$ on average (Fig. 12b), with little variability in the extreme $(\mu+1 \sigma)$ values (not shown). Wind speeds between sunset and sunrise were low and relatively consistent (on average $0.5-0.7 \mathrm{~m} \mathrm{~s}^{-1}$ ), from the ESE (Fig. 12d and e), with around $25 \%$ cloud cover predicted and no measured rainfall (Fig. 12f), all consistent with anticyclonic synoptic conditions. The high variability in NOAA GDAS nocturnal cloud amount (Fig. 12c) may be associated with fog that frequently forms under PTI conditions. There was no snow during the 2016-2017 winter, which would otherwise have led to stronger and longerlasting persistent temperature inversion conditions. Results from a companion study to this one, still in preparation, indicate that snow cover in the following 2017-2018 winter reduced mean winter rates of radon emission by a factor of $2-3$. The mean atmospheric pressure during PTI events was $\sim 994 \mathrm{hPa}$, compared to $\sim 986 \mathrm{hPa}$ for non-PTI conditions, confirming the prevalence of anticyclonic conditions.

The mean diurnal temperature amplitude $\left(6^{\circ} \mathrm{C}\right)$ of TGM PTI events was $1{ }^{\circ} \mathrm{C}$ larger than that of the RBM events, the 

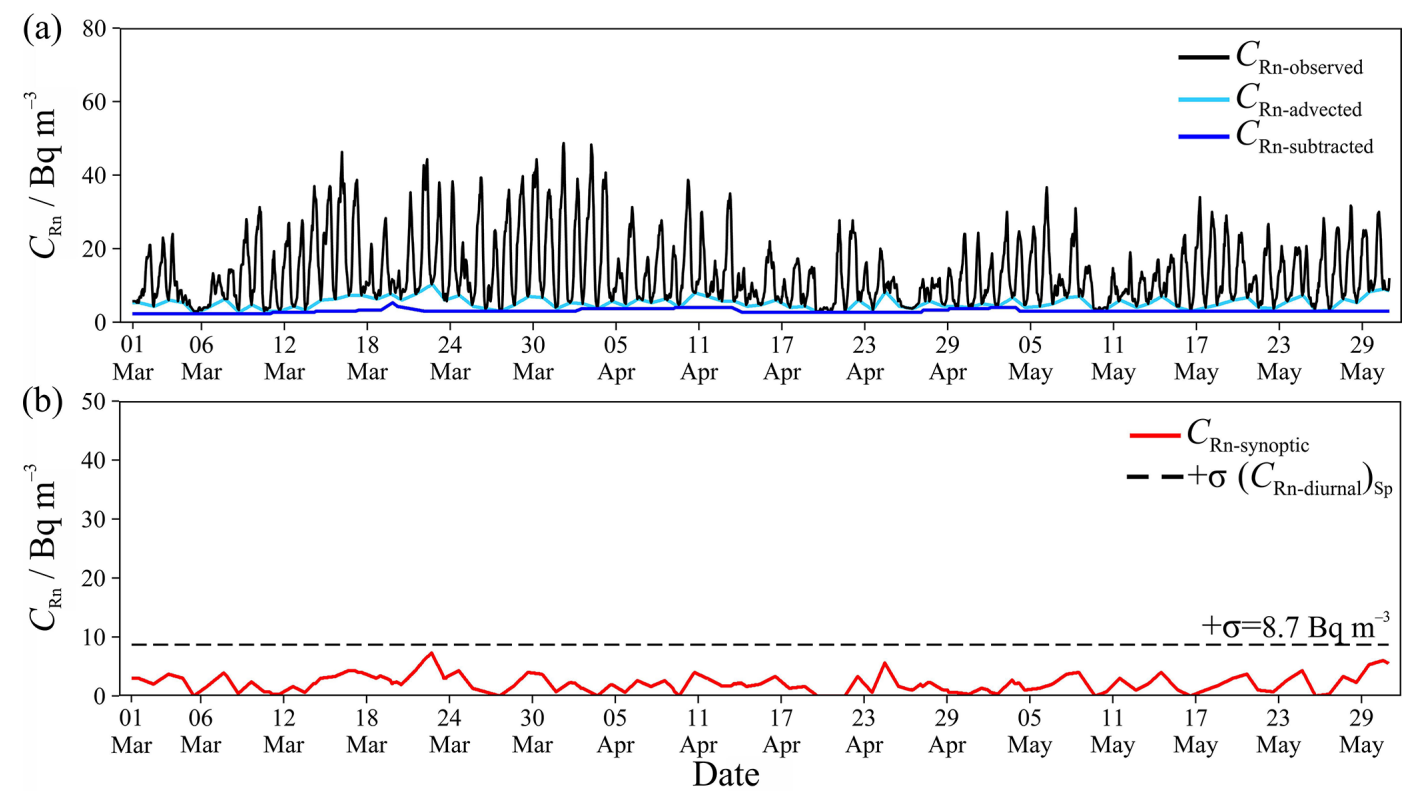

Figure 7. (a) Hourly mean observed radon concentrations, the advected radon contribution with subtracted radon indicated, and (b) isolated synoptic timescale radon contribution in spring with the standard deviation $(+\sigma)$ of the diurnal contribution indicated. No persistent temperature inversion events were detected by the RBM this season.
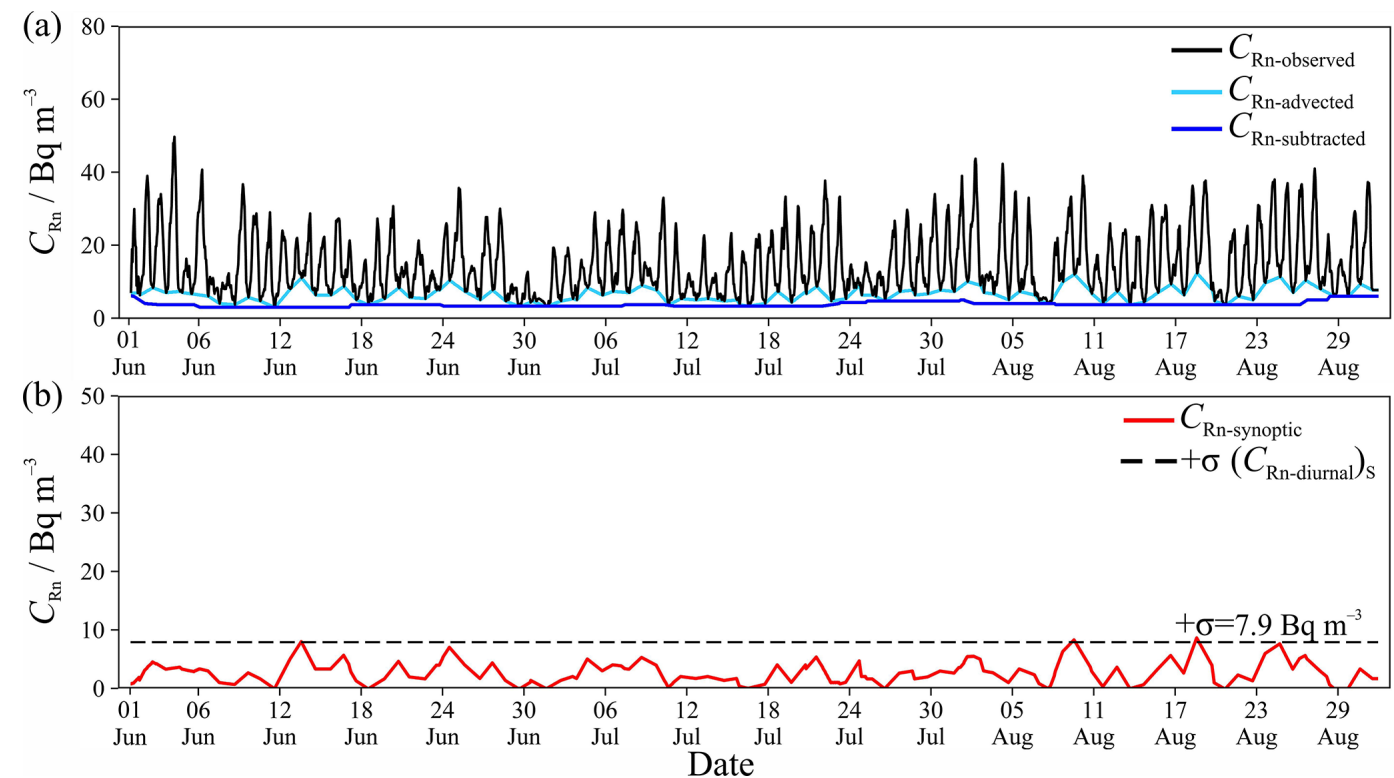

Figure 8. (a) Hourly mean observed radon concentrations, the advected radon contribution with subtracted radon indicated, and (b) isolated synoptic timescale radon contribution in summer with the standard deviation $(+\sigma)$ of the diurnal contribution indicated. No persistent temperature inversion events were detected by the RBM this season.

diurnal amplitude of relative humidity $(20 \%)$ was $5 \%$ larger than that of the RBM events, and nocturnal extreme relative humidity values were less consistent (Fig. 12a and b; green vs. red lines). Diurnal minimum wind speeds were slightly higher $\left(0.6-0.7 \mathrm{~m} \mathrm{~s}^{-1}\right)$, and had a considerably larger diurnal amplitude than that of the RBM events (Fig. 12d). The TGMselected PTI days had more cloud cover (by $10 \%-15 \%$ ) and experienced some rainfall (Fig. 12c and f), which is very uncharacteristic of stable (typically anticyclonic) conditions. It should be noted that many of the differences between RBM and TGM PTI events selected in winter can be attributed to the single event $\left(I_{4}\right)_{\mathrm{W}}$, for which the mean temperature gradient indicated a lesser degree of stratification (Fig. 4). 


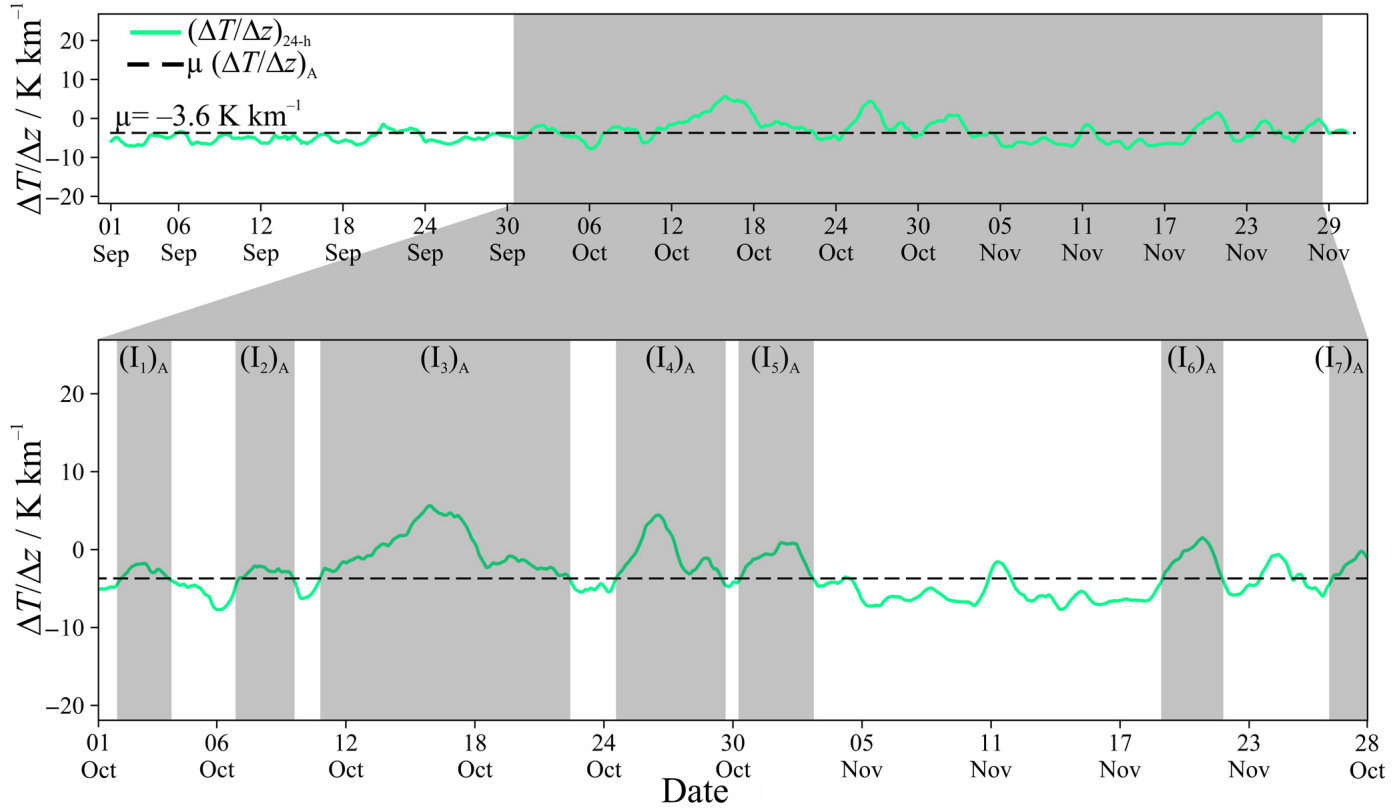

Figure 9. The $24 \mathrm{~h}$ running mean of the pseudo-vertical temperature gradient in autumn; seven persistent temperature inversion events $\left(I_{i}\right)_{\mathrm{A}}$ detected by the TGM are shown in the shaded section and enlarged in the breakout panel beneath; see text in Sect. 2.3.2 for details.

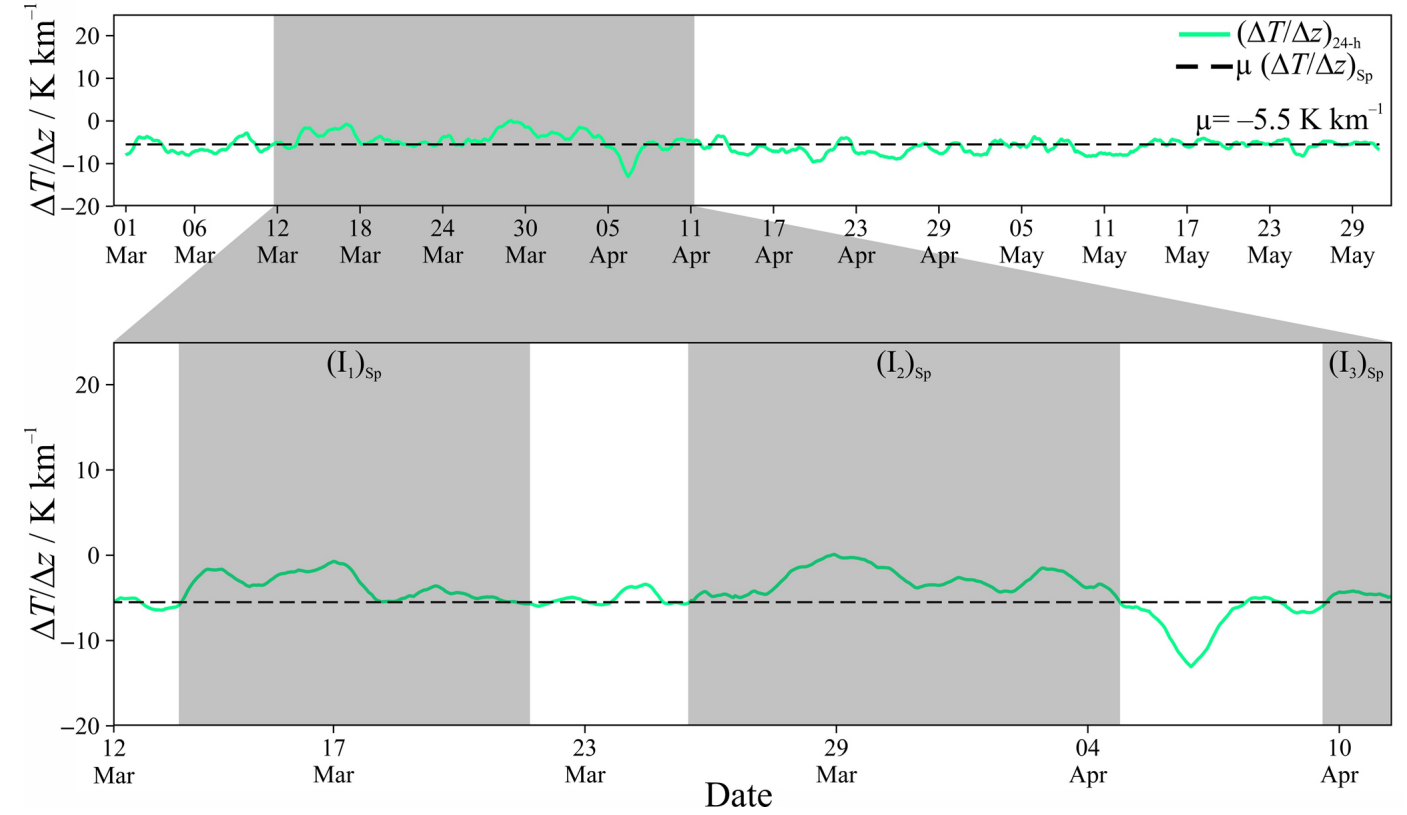

Figure 10. The $24 \mathrm{~h}$ running mean of the pseudo-vertical temperature gradient in spring; three persistent temperature inversion events $\left(I_{i}\right)_{S p}$ detected by the TGM are shown in the shaded area and enlarged in the breakout panel beneath; see text in Sect. 2.3.2 for details.

Atmospheric pressure (not shown) was also elevated for all $\left(I_{i}\right)_{\mathrm{W}}$ except $\left(I_{4}\right)_{\mathrm{W}}$.

The composite diurnal meteorological conditions associated with the autumn PTI events (RBM and TGM) and autumn mean are shown in Fig. 13. Of particular note, wind speeds for the autumn RBM PTI events were even lower than those in winter, with broad $\geq 12 \mathrm{~h}$ periods of consistently low wind speeds $\left(0.1-0.3 \mathrm{~m} \mathrm{~s}^{-1}\right)$ throughout the night, but also from the ESE (Fig. 13d and e; red lines). The mean diurnal amplitude of wind speed on autumn PTI days selected by RBM was $\sim 0.5 \mathrm{~m} \mathrm{~s}^{-1}$ compared to $\sim 2.5 \mathrm{~m} \mathrm{~s}^{-1}$ for non-PTI autumn days (Fig. 13d). By comparison, PTI events identified by the TGM had shorter nocturnal periods of lowest wind speed (5-8 h) (Fig. 13d), with daytime $\mu+1 \sigma$ values of 


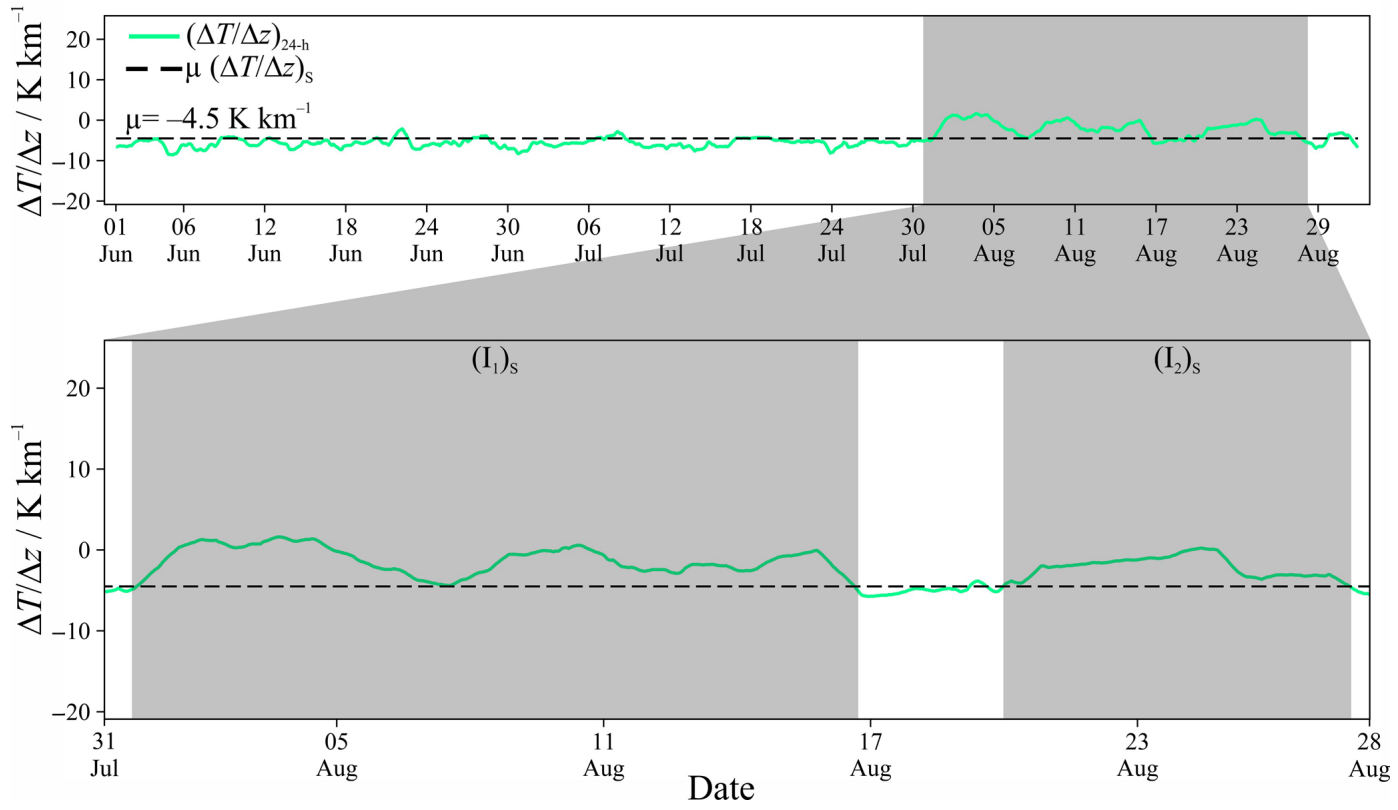

Figure 11. The $24 \mathrm{~h}$ running mean of the pseudo-vertical temperature gradient in summer; two persistent temperature inversion events $\left(I_{i}\right)_{\mathrm{S}}$ detected by the TGM are shown in the shaded section and enlarged in the breakout panel beneath; see text in Sect. 2.3.2 for details.

(a)

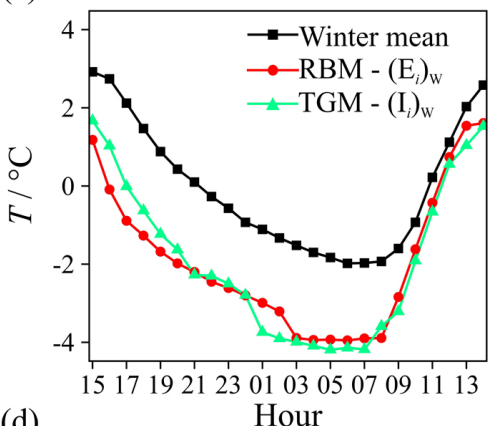

(d)

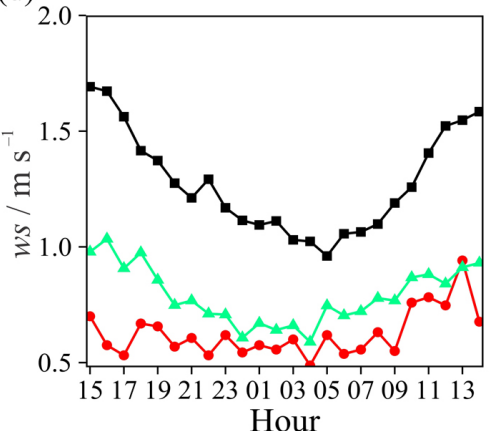

(b)

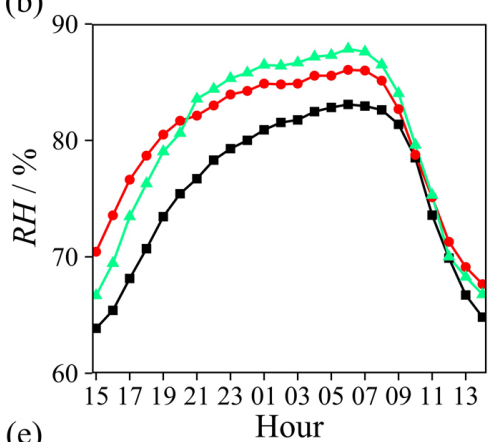

(e)

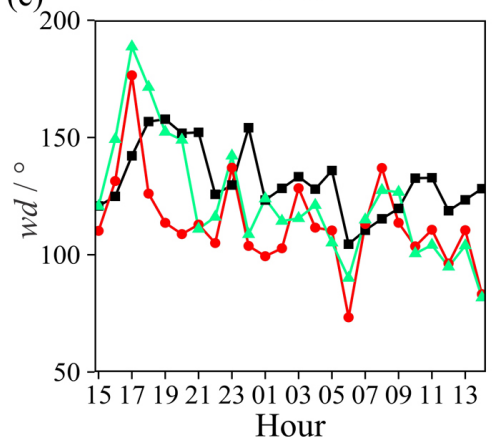

(c)

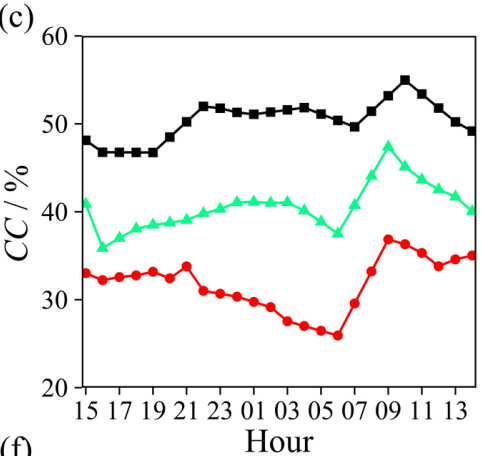

(f)

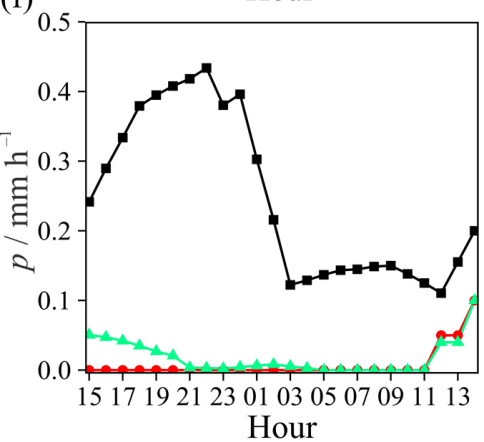

Figure 12. Diurnal composites, based on hourly means, of (a) air temperature, (b) relative humidity, (c) cloud cover, (d) wind speed, (e) wind direction, and (f) precipitation, for winter mean, and persistent temperature inversion events detected in winter by the RBM and TGM.

2-3.2 $\mathrm{m} \mathrm{s}^{-1}$ (not shown). Between 00:00 and 05:00 LT nearsurface air temperature changed very slowly on RBM PTI nights (around $-0.1^{\circ} \mathrm{Ch}^{-1}$; Fig. 13a) compared with around $-0.4^{\circ} \mathrm{Ch}^{-1}$ for non-PTI nights. On the other hand, diurnal composites of meteorological quantities corresponding to the autumn TGM PTI events showed moderate-amplitude temperature variability $\left(5\right.$ to $\left.15^{\circ} \mathrm{C}\right)$, a $37 \%$ amplitude change in relative humidity (with relatively consistent peak values between 01:00 and 06:00 LT) (Fig. 13a, b). Relatively high cloud cover amounts were associated with autumn TGM 
(a)

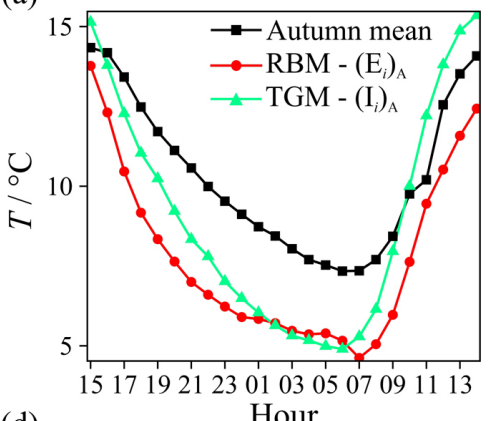

(d)

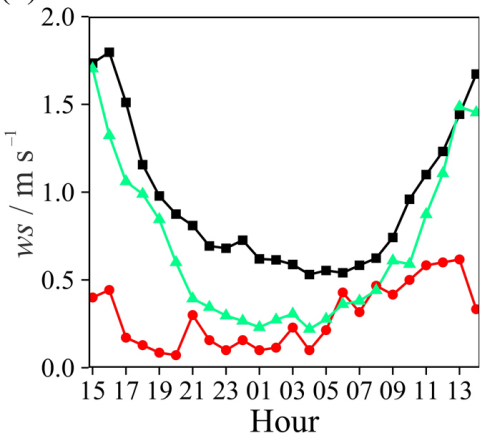

(b)

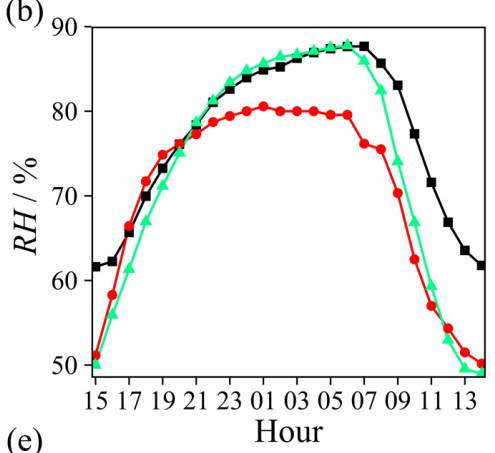

(e)

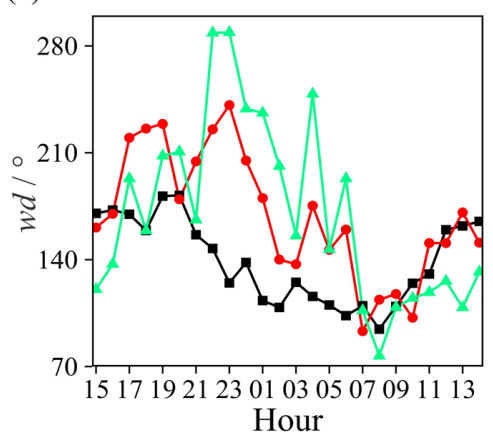

(c)

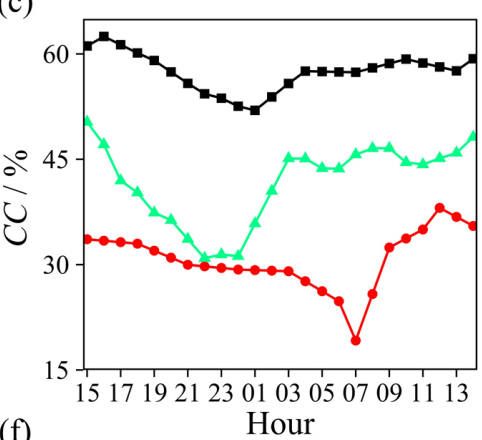

(f)

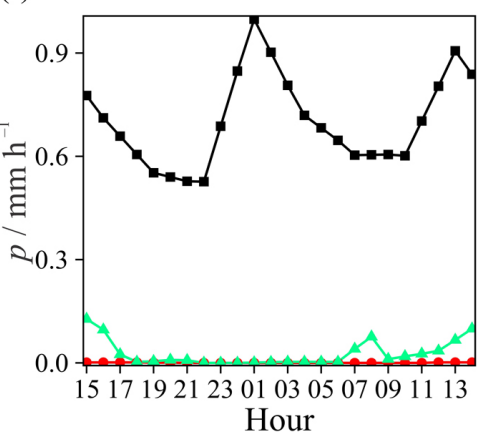

Figure 13. Diurnal composites, based on hourly means, of (a) air temperature, (b) relative humidity, (c) cloud cover, (d) wind speed, (e) wind direction, and (f) precipitation, for autumn mean, and persistent temperature inversion events detected in autumn by the RBM and TGM.

Table 4. Persistent temperature inversion events $\left(I_{i}\right)$ by season (winter, W; spring, Sp; summer, S; autumn, A) detected by pseudovertical temperature gradient method (TGM), including time period and duration.

\begin{tabular}{|c|c|c|}
\hline Event & Persistent inversion period & Duration \\
\hline$\left(\mathbf{I}_{1}\right)_{\mathbf{W}}$ & 17/12/2016-19/12/2016 & $62 \mathrm{~h}(2.6 \mathrm{~d})$ \\
\hline$\left(\mathbf{I}_{2}\right)_{\mathbf{W}}$ & 20/12/2016-27/12/2016 & $184 \mathrm{~h}(7.6 \mathrm{~d})$ \\
\hline$\left(\mathbf{I}_{3}\right)_{\mathbf{W}}$ & 29/12/2016-02/01/2017 & $93 \mathrm{~h}(3.8 \mathrm{~d})$ \\
\hline$\left(I_{4}\right)_{\mathrm{W}}$ & 20/01/2017-24/01/2017 & $89 \mathrm{~h}(3.7 \mathrm{~d})$ \\
\hline$\left(\mathbf{I}_{5}\right)_{\mathbf{W}}$ & 27/01/2017-02/02/2017 & $152 \mathrm{~h}(6.3 \mathrm{~d})$ \\
\hline$\left(I_{1}\right)_{\mathrm{Sp}}$ & 13/03/2017-21/03/2017 & $191 \mathrm{~h}(8 \mathrm{~d})$ \\
\hline$\left(I_{2}\right)_{\mathrm{Sp}}$ & 25/03/2017-04/04/2017 & $246 \mathrm{~h}(10.3 \mathrm{~d})$ \\
\hline$\left(I_{3}\right)_{\mathrm{Sp}}$ & 25/03/2017-04/04/2017 & $48 \mathrm{~h}(2 \mathrm{~d})$ \\
\hline$\left(I_{1}\right)_{\mathrm{S}}$ & $31 / 07 / 2017-16 / 08 / 2017$ & $386 \mathrm{~h}(16 \mathrm{~d})$ \\
\hline$\left(I_{2}\right)_{\mathrm{S}}$ & 20/08/2017-27/08/2017 & $186 \mathrm{~h}(7.8 \mathrm{~d})$ \\
\hline$\left(I_{1}\right)_{\mathrm{A}}$ & 01/10/2017-03/10/2017 & $51 \mathrm{~h}(2.1 \mathrm{~d})$ \\
\hline$\left(I_{2}\right)_{\mathrm{A}}$ & 07/10/2017-09/10/2017 & $59 \mathrm{~h}(2.5 \mathrm{~d})$ \\
\hline$\left(\mathbf{I}_{3}\right)_{\mathbf{A}}$ & 10/10/2017-22/10/2017 & $277 \mathrm{~h}(11.5 \mathrm{~d})$ \\
\hline$\left(I_{4}\right)_{\mathrm{A}}$ & 24/10/2017-29/10/2017 & $117 \mathrm{~h}(4.9 \mathrm{~d})$ \\
\hline$\left(I_{5}\right)_{\mathrm{A}}$ & $30 / 10 / 2017-02 / 11 / 2017$ & $79 \mathrm{~h}(3.3 \mathrm{~d})$ \\
\hline$\left(\mathbf{I}_{\mathbf{6}}\right)_{\mathbf{A}}$ & 19/11/2017-21/11/2017 & $65 \mathrm{~h}(2.7 \mathrm{~d})$ \\
\hline$\left(I_{7}\right)_{\mathrm{A}}$ & 26/11/2017-28/11/2017 & $50 \mathrm{~h}(2.1 \mathrm{~d})$ \\
\hline
\end{tabular}

Note: the events in bold were also detected by the radon-based method (RBM).
PTI events (around 40\%), with occasional rainfall recorded (Fig. 13c and f). In contrast to results from the TGM, from prior to sunset until several hours after sunrise, while some fog or cloud occurred, no rainfall was recorded at all under PTI conditions identified by the RBM in autumn (Fig. 13c and $f$ ).

Diurnal composites of meteorological conditions associated with spring and summer PTI events selected only by TGM and for mean spring and summer seasons are summarized in Figs. 14 and 15. The spring air temperature, relative humidity, and wind speed diurnal composites show gradual and relatively consistent changes throughout the night to brief (not broad) minimum-maximum values around 05:0006:00 LT, followed by a rapid change after sunrise (Fig. 14a, $\mathrm{b}$, and d). The days identified here as PTI events actually correspond with days on which a strongly stable nocturnal boundary layer has formed, which is then broken up in the morning by strong convection, rather than persistent inversion conditions. Further in support of this observation, only between 00:00 and 05:00 LT on the spring days identified by the TGM as PTI events did the wind direction switch to ESE (Fig. 14e), the expected direction of katabatic drainage at this site. The large mean diurnal amplitudes of temperature $\left(\sim 13^{\circ} \mathrm{C}\right)$, relative humidity $(\sim 45 \%)$, and wind speed $\left(\sim 2.5 \mathrm{~m} \mathrm{~s}^{-1}\right)$ in spring (Fig. 14a, b, and d) were not consistent with characteristics usually associated with PTI events. Similar characteristics were observed within the diurnal composite plots of summer PTI events identified by 
the TGM (Fig. 15), indicative of stable nocturnal conditions (though not as strong in summer) that rapidly become convective after sunrise, rather than persisting as stable events throughout the day. Further evidence that the TGM was even less selective of nocturnally stable conditions is the frequent rainfall events observed on the nights in question (Fig. 15f).

By definition, PTI events should not exhibit strong diurnal cycles of temperature and relative humidity, should have consistently light to calm nocturnal wind speeds, and, since little daytime convective mixing is expected, daytime wind speeds should also be relatively light. Furthermore, since they usually occur under anticyclonic synoptic conditions, when regional subsidence prevails, rainfall is not expected.

In summary, while no PTI events identified by the RBM in winter or autumn were missed by the TGM (Tables 3 and 4), it is clear that the TGM is less selective of truly persistently stable conditions than the RBM. However, the TGM classified a number of other periods in winter and autumn as PTI events, and also considered that the $\left(I_{3}\right)_{\mathrm{A}}$ was longer lasting than predicted by the RBM. This shortcoming is likely attributable to the degree of validity of the assumptions on which the TGM is based for the Ljubljana basin. In spring and summer (Figs. 14 and 15) some assumptions of the TGM are less valid (i.e., less distinction between temperatures at different elevations), causing the method to produce misleading results. Large temperature gradients on very stable nights push daily mean values well above the seasonal mean. For consecutive strongly stable nights, under anticyclonic conditions, this is incorrectly interpreted as a PTI event by the TGM.

\subsection{Advantages and limitations of radon-based method (RBM)}

The RBM relies upon accurate characterization of afternoon minimum radon concentrations. In this regard, measurement quality and time series analysis are important. The lower limit of detection of commercial, portable radon detectors such as the AlphaGUARD (LLD 2-3 $\mathrm{Bq} \mathrm{m}^{-3}$ ) is 2 orders of magnitude poorer than that of research-grade twofilter radon detectors (LLD $\sim 0.02 \mathrm{~Bq} \mathrm{~m}^{-3}$; Chambers et al., 2014). Compared with sub-diurnal variability this necessitates smoothing of radon observations if using a commercial instrument, the extent of which is likely to be application/site-specific. An alternative, but more expensive, solution would be to make vertical radon gradient measurements using research-grade detectors. This would ensure the most accurate, and simple, separation of diurnal (mixing-related) and synoptic (fetch-related) contributions to observed radon concentrations.

The amount of radon that accumulates over a night or a given synoptic PTI event is directly related to the seasonal average radon flux. By performing the RBM separately for each season and year, long-term (i.e., seasonal mean) changes of the terrestrial radon flux from one season or year to the next (as may be driven by changes in mean soil moisture, snow cover, or soil freezing) do not affect the comparative seasonal efficacy of the technique, making it seasonally independent. However, large spatial variability in the radon source function (as experienced between land and open water bodies) has the potential to prevent this technique from accurately identifying PTI events, but only for study regions located on (or close to, i.e., $\leq 10 \mathrm{~km}$ ) the coast. For non-coastal regions, the longevity of radon's parent $\left({ }^{226} \mathrm{Ra}\right.$, half-life 1600 years) ensures that the technique can be applied consistently over long periods and - when enough PTI events have been observed within a given season - provide a means of objectively assessing their severity.

Compared to the pseudo-vertical temperature gradient method, which requires input from multiple ground-based weather stations (Whiteman et al., 2004), single-height radon monitoring, from a single monitoring station near the bottom of the basin/valley, clearly provides a simple, economical, and low-maintenance means by which to identify persistent temperature inversion events with a substantially higher degree of success than some contemporary meteorological approaches.

\subsection{Advantages and limitations of the pseudo-vertical temperature gradient method (TGM)}

For the Ljubljana basin the TGM was found to not always be a reliable means of detecting PTI events. This was mainly due to limited validity of the necessary assumptions. The assumption of a horizontally homogeneous temperature field was often invalid in the case of the high-elevation sites, where a variety of mesoscale processes, including drainage flows, nocturnal jets, and intermittent turbulence (Whiteman et al., 2004; Williams et al., 2013) limit the ability to derive representative vertical temperature gradients from spatially separated locations at different elevations. Furthermore, the assumption of distinct differences between temperatures of the different elevation groups based on daily means was typically only valid in winter (Table 2).

Consequently, for most of the year the TGM was only able to reliably identify stable conditions in the boundary layer at night, when buoyancy or gravitational effects tend to produce horizontal isotherms (Whiteman et al., 2004). However, pseudo-vertical temperature profiles are useful for identifying extended periods of strongly stable conditions based on $24 \mathrm{~h}$ data in winter (Largeron and Staquet, 2016a). According to Whiteman et al. (2004), the TGM tends to be more representative of PTI events when the study region has snow cover. A uniform cover of snow reduces the temperature contrasts usually associated with radiation receipt on different aspect slopes and different types of ground cover, helping to maintain stability over the diurnal cycle (Whiteman et al., 2004). The reduced accuracy of the technique in the SAB during the 2016-2017 winter season may be attributable in part to a lack of snow cover that winter. 
(a)

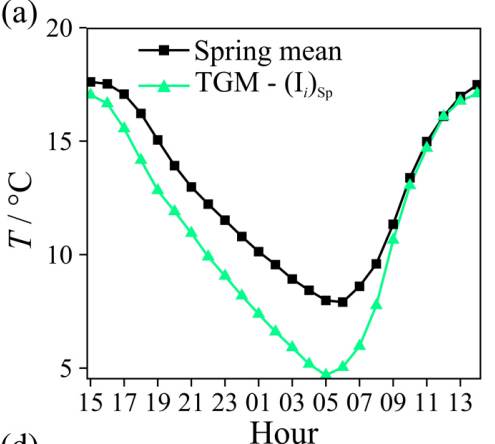

(d)

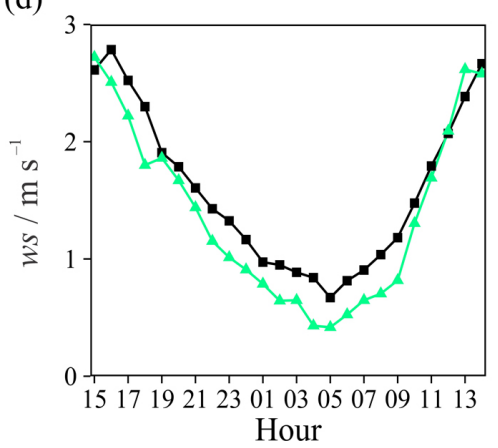

(b)

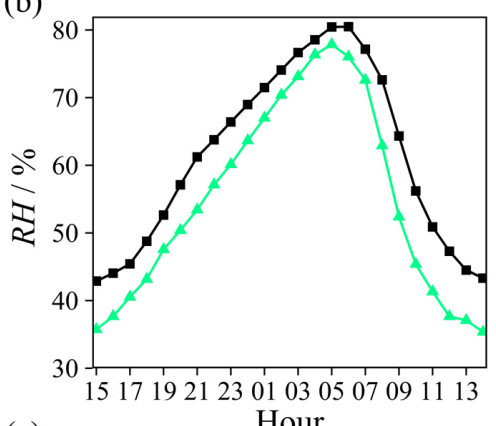

(e)

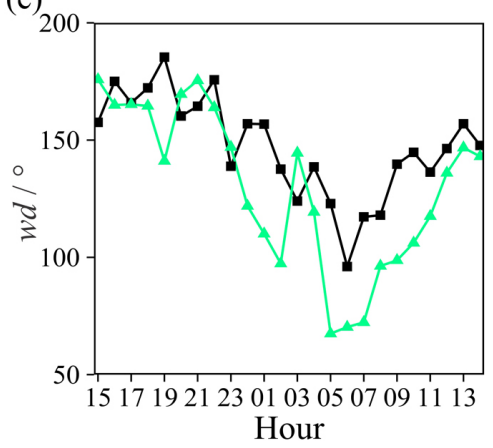

(c)

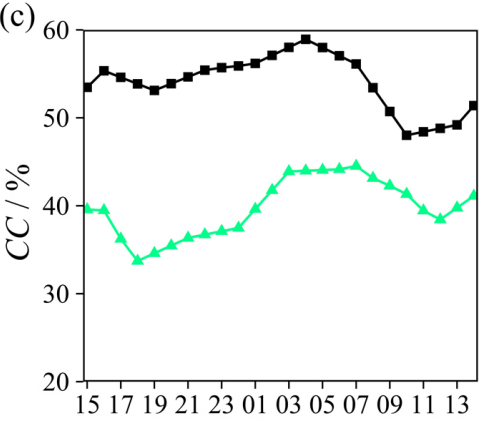

(f)

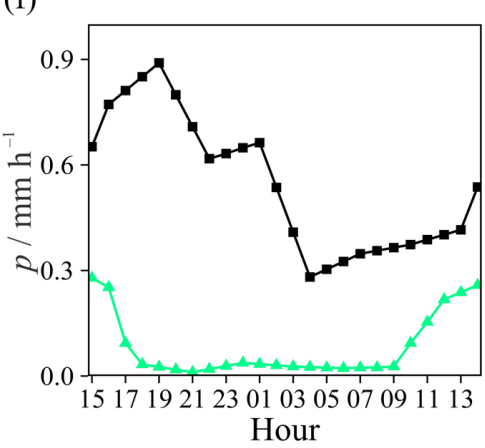

Figure 14. Diurnal composites, based on hourly means, of (a) air temperature, (b) relative humidity, (c) cloud cover, (d) wind speed, (e) wind direction, and (f) precipitation, for spring mean, and persistent temperature inversion events detected in spring by the TGM. No persistent temperature inversion events were detected by the RBM this season.

(a)

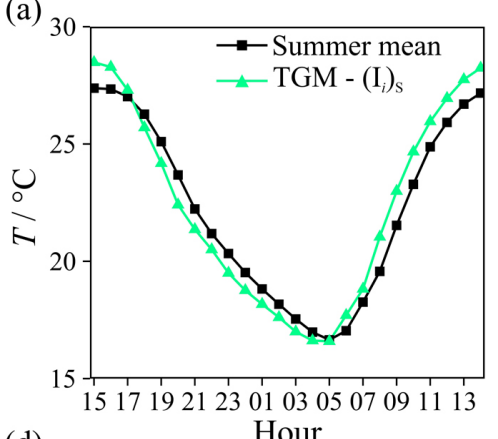

(d)

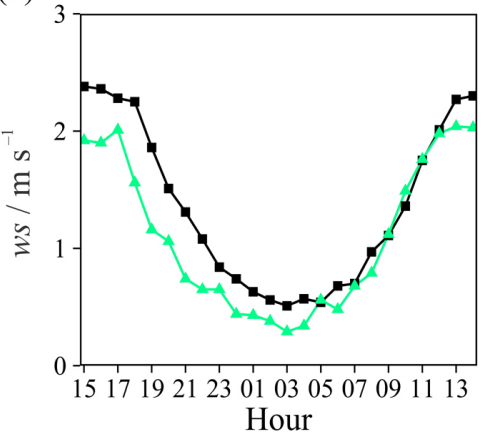

(b)

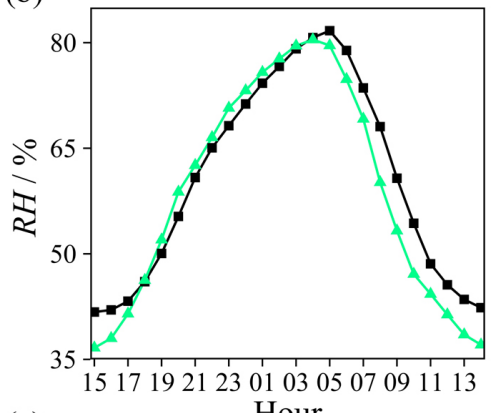

(e)

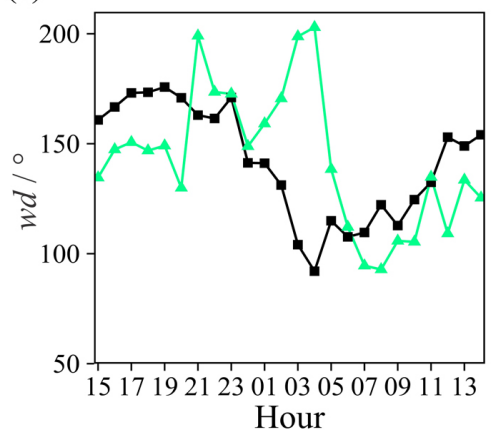

(c)

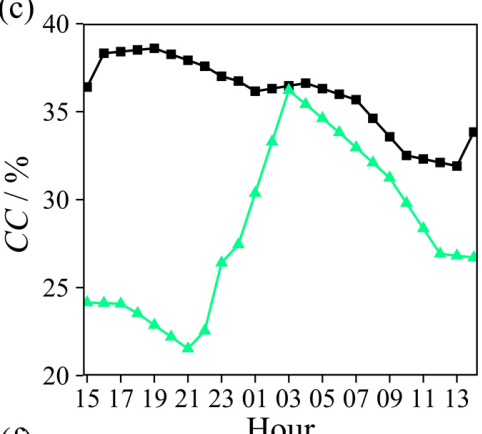

(f)

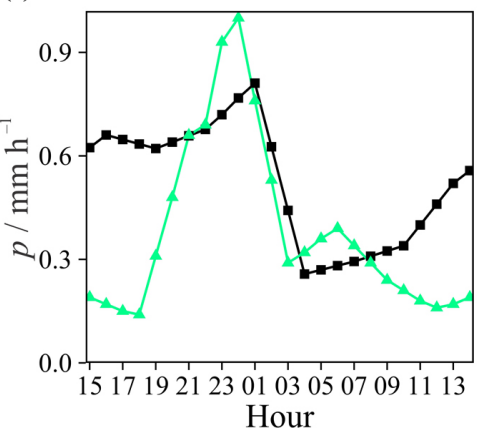

Figure 15. Diurnal composites, based on hourly means, of (a) air temperature, (b) relative humidity, (c) cloud cover, (d) wind speed, (e) wind direction, and (f) precipitation, for summer mean, and persistent temperature inversion events detected in summer by the TGM. No persistent temperature inversion events were detected by the RBM this season. 
The number and location of ground-based weather stations are important factors of the TGM; stations should be placed in all directions (north, east, south, and west). The Ljubljana basin automatic weather station network lacked stations in the south, which may have contributed to the poor performance of the technique. Large open regions of complex topography, more exposed to synoptic wind influences, are not well suited to the TGM (Whiteman et al., 2004).

Overall, the inability of the TGM to perform equally well in all seasons and its lack of appropriate selectivity of truly persistent stable conditions (regarding event number, duration, and strength) in winter and autumn compared to the RBM were the most serious limitations.

\subsection{Urban air quality during persistent temperature inversion events}

In some regions of Europe with complex terrain, urban air quality is strongly influenced by PTI events. For example, of 29 separate air pollution events in the Eordaia mountain basin of northeastern Greece analyzed by Triantafyllou (2001), more than half occurred under PTI conditions. Other European regions in which cold season PTI events have been studied in complex topographical locations include Athens, Greece (Kassomenos and Koletsis, 2005); Cracow, Poland (Bielec-Bąkowska et al., 2011; Jędruszkiewicz et al., 2017); Grenoble (Largeron and Staquet, 2016a) and Chamonix-Mont-Blanc (Chemel et al., 2016), France; Ljubljana (Petkovšek, 1978, 1985, 1992; Rakovec et al., 2002) and Ajdovščina (Longlong et al., 2016), Slovenia; and the Po Valley region, Italy (Marcazzan et al., 2001). The pollution events in each of these studies were characterized by stable stratification and subsidence, suppressing vertical mixing while the confining topography and weak-to-calmgradient winds prevented advection and favored air stagnation (Kukkonen et al., 2005). Under such circumstances the accumulation of primary pollutants and formation of secondary pollutants not only poses adverse pulmonary and cardiovascular health effects, but also greatly reduces the visibility (Largeron and Staquet, 2016a, b; Reddy et al., 1995; Silcox et al., 2012; Whiteman et al., 2014) and can lead to hazardous episodes of persistent freezing rain, drizzle, or fog (Petkovšek, 1974).

In order to better compare the suitability of the RBM and TGM methods of PTI identification for air quality assessment of subalpine basin cities, hourly observations of $\mathrm{PM}_{10}$ in Ljubljana city were analyzed. The diurnal and seasonal variability of $\mathrm{PM}_{10}$ in Ljubljana are shown in Fig. 16 for all conditions (seasonal mean), as well as for PTI conditions as determined by the RBM and TGM.

Overall, the annual mean $\mathrm{PM}_{10}$ concentration for Ljubljana was $28 \mu \mathrm{g} \mathrm{m}^{-3}$, and the average daily-maximum $\mathrm{PM}_{10}$ concentration for winter was $53 \mu \mathrm{g} \mathrm{m}^{-3}$, which exceeded the WHO and EEA standard of maximum daily concentration $50 \mu \mathrm{g} \mathrm{m}^{-3}$ (EEA, 2016, 2017; Ivančič and Vončina, 2015).
Compared with seasonal mean values, there was a significant increase in $\mathrm{PM}_{10}$ concentrations under cold season PTI conditions, as a consequence of poor atmospheric mixing over the whole diurnal cycle (Fig. 16a and b). Compared to the RBM, the TGM underestimated peak hourly $\mathrm{PM}_{10}$ concentrations of PTI events by 13 and $11 \mu \mathrm{g} \mathrm{m}^{-3}$, in winter and autumn, respectively. In winter $\mathrm{PM}_{10}$ concentrations for PTI events were underestimated across the entire diurnal cycle by the TGM, and for around $18 \mathrm{~h}$ of the composite day in autumn. These differences would lead to significantly different levels of daily-mean exposure for residents. The amplitude of the diurnal cycle of $\mathrm{PM}_{10}$ for TGM PTI events was $4 \mu \mathrm{g} \mathrm{m}^{-3}$ larger than that of RBM events; attributable to more mixing at night and slightly stronger daytime atmospheric mixing in the case of TGM PTI events (Fig. 16a and b).

In the warmer months, neither the daily mean $\mathrm{PM}_{10}$ values for seasonal mean nor TGM PTI periods exceeded guideline values (Fig. 16c and d). Diurnal cycles of PM 10 for TGM PTI events at these times were characterized by higher concentrations in the morning (06:00-08:00 LT) and evening (18:0020:00 LT) rush hours. In the afternoons when the ABL was deepest, concentrations of $\mathrm{PM}_{10}$ were the lowest due to typical diurnally changing as opposed to persistent atmospheric mixing conditions.

The seasonal inconsistency of the TGM for PTI identification, in addition to its lack of selectivity of persistently stable conditions in the cold seasons, renders it an unsuitable tool for air quality management purposes in subalpine basin environments.

Our findings, based on the RBM of PTI event identification, indicated that PTI events span $27 \%$ of the cold season (winter and autumn) in the subalpine Ljubljana basin, making it one of the critical European regions with regard to urban air quality issues. Due to domestic heating requirements, the increased use of vehicles, and the production of energy from the thermal power plant, pollutant emissions drastically increase in the cold season. Adverse dispersion conditions as a result of frequent cold season PTI events favor the accumulation of pollutants, leading to severe health issues. For these reasons, improving knowledge about the frequency, duration, intensity, and seasonal variability of PTI events is required for decision makers when considering the need for emission mitigation strategies.

The technique developed in this study adds another dimension to contemporary radon-based methods of characterizing the atmospheric mixing state (Chambers et al., 2015, 2019; Williams et al., 2016) that were developed for less complex topographic regions. Under PTI conditions contributions to radon concentration variability on synoptic timescales can dominate variability on diurnal timescales, thereby violating a fundamental assumption of the approach employed by Chambers et al. (2019). Consequently, nocturnal periods under PTI conditions would be misclassified below their actual degree of atmospheric stability. Applying the RBM of PTI classification to observations in a subalpine basin set- 
(a)

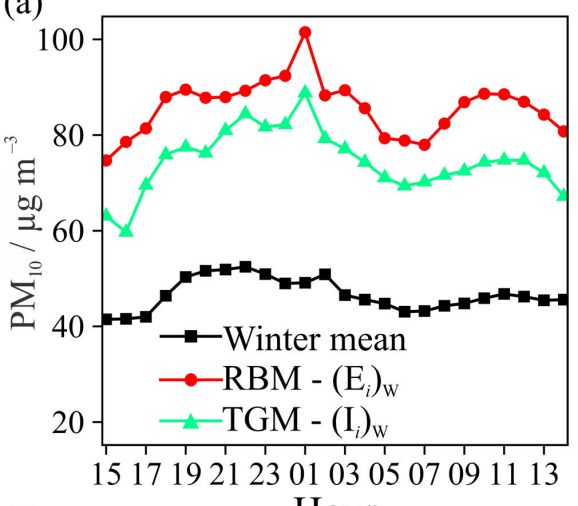

(c)

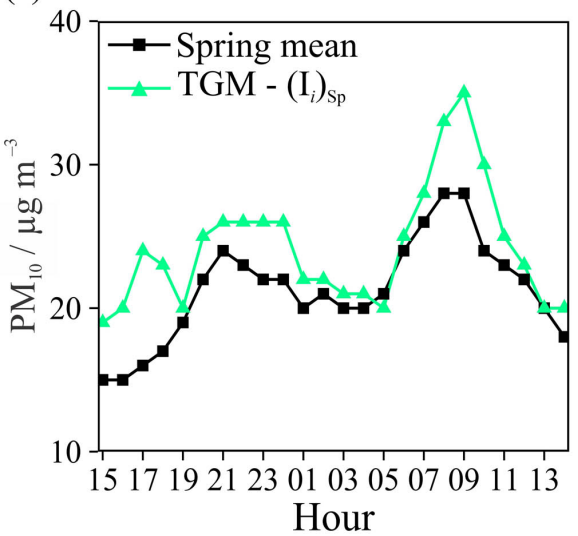

(b)

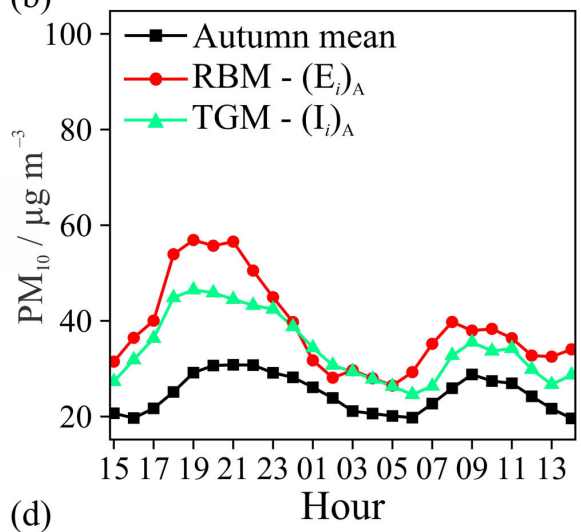

(d)

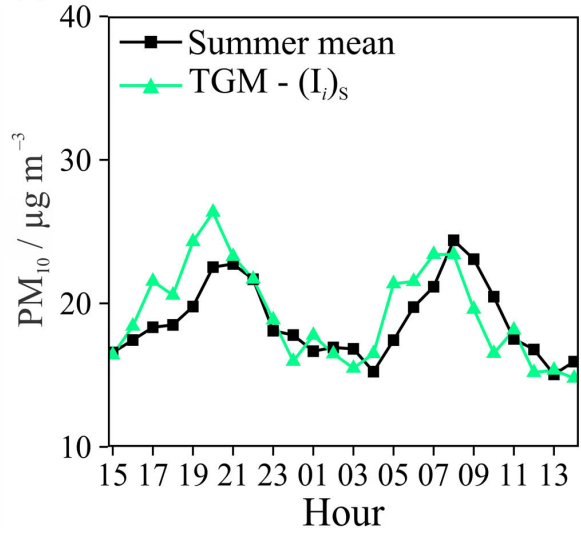

Figure 16. Diurnal $\mathrm{PM}_{10}$ composites, based on hourly means, for: (a) winter, (b) autumn, (c) spring, and (d) summer, for all conditions (seasonal mean) and for persistent temperature inversion events detected by the RBM and TGM.

ting after first classifying the data according to the scheme of Chambers et al. (2019) would enable clear identification of the misclassified events for separate analysis. The combined application of these two approaches using a complete suite of criteria pollutants in Ljubljana city will be the subject of a separate investigation.

\section{Conclusions}

The aim of this study was to determine a reliable and seasonally independent method to identify persistent temperature inversion events in the subalpine basin setting of Ljubljana, based on observations over the period December 2016November 2017. To this end, two methods were compared: (i) a new radon-based method developed and tested in this study and (ii) a previously published pseudo-vertical temperature gradient method.

Development of the radon-based method required an understanding of the various timescales contributing to variability in the 1-year hourly radon time series (sub-diurnal, diurnal, synoptic, and greater than synoptic). The method is applied in four steps: (i) minimize sub-diurnal radon variability, (ii) identify the fetch-related (synoptic-scale) radon vari- ability, (iii) isolate the synoptic-scale from larger timescale variability, and (iv) identify persistent temperature inversion events using the seasonal standard deviation of diurnal timescale radon variability as an event threshold with $\mathrm{a} \geq 48 \mathrm{~h}$ persistence requirement. The method was applied separately for each season in order to account for seasonal changes in the radon source function, day length, and atmospheric mixing.

The existing pseudo-vertical temperature gradient method to identify PTI events was applied using 1 year of measurements from eight automatic weather stations, within three distinct elevation categories, distributed around the base and on the sidewalls of the basin. The technique considers dailymean temperature gradients between stations in different elevation categories. The applicability of the technique is contingent upon two key assumptions: (i) horizontal homogeneity of air temperature between stations within the same elevation category, and (ii) clear and consistent distinction of temperature between stations in different elevation categories.

Over the year, the radon-based method identified six PTI events (four in winter, two in autumn). No PTI events were identified in spring or summer. By comparison, the pseudovertical temperature gradient method identified 17 PTI events (five in winter, three in spring, two in summer, and seven in 
autumn). All six events identified by the radon-based method were also identified by the pseudo-vertical temperature gradient method. Each of the events identified by both methods were associated with persistent strongly stable conditions, light to calm winds (typically $0.2-0.6 \mathrm{~m} \mathrm{~s}^{-1}$ ), modest amplitudes of diurnal temperature and relative humidity cycles, relatively consistent nocturnal conditions, and no precipitation. On the other hand, the additional 11 events detected by the pseudo-vertical temperature gradient method were characterized by somewhat mixed meteorological conditions: larger amplitude diurnal cycles of temperature, humidity, and wind speed, daytime wind speeds of up to $4 \mathrm{~m} \mathrm{~s}^{-1}$, and frequent nocturnal rainfall. The comparative suitability of the RBM and TGM of PTI event identification in air quality studies was determined using hourly $\mathrm{PM}_{10}$ observations. Peak hourly-mean $\mathrm{PM}_{10}$ concentrations of TGM PTI events were $13(11) \mu \mathrm{g} \mathrm{m}^{-3}$ lower than those of RBM PTI events in winter (autumn). Only peak hourly-mean values of RBM PTI events exceeded $100 \mu \mathrm{g} \mathrm{m}^{-3}$, the upper threshold of lowlevel short-term $\mathrm{PM}_{10}$ exposure according to World Health Organization guidelines.

The RBM was found to be more reliable and seasonally independent than the TGM. The inaccuracy and inconsistency of the TGM was thought to be primarily attributable to the requisite assumptions, which were not consistently met throughout the year. We demonstrated that the RBM is a convenient, simple, and economical means of consistently identifying PTI events in complex topographies (e.g., basins or valleys) regardless of season. The consistency and accuracy of this method has the potential to significantly increase the understanding of meteorological processes resulting in air pollution episodes. Once a representative number of PTI events have been observed within each season, this technique also has the potential to objectively assess the relative strength of PTI events. As such, the RBM has the potential to become a key tool in urban centers for air quality management and assessing public health risks.

Data availability. Meteorological and air quality data are collected and supplied by the National Meteorological Service at the Environmental Agency of the Republic of Slovenia (ARSO) (https://meteo. arso.gov.si/, last access: 11 August 2019). Atmospheric radon data will be made available on request.

Author contributions. The investigation was jointly conceptualized by DK, SC, and JV. Radon monitoring instrumentation was deployed and managed by DK and JV. Data collection and curation was performed by DK. Formal data analysis was performed by DK and SC. Acquisition of funding for the research was arranged by JV. The research methodology was jointly developed by DK and $\mathrm{SC}$ and investigation jointly conducted by DK and JV. The project was administered by JV, with JV and SC responsible for supervision. All visualization of data, concepts, and results was performed by DK. DK wrote the complete original draft of the paper, which was subsequently edited and reviewed jointly by DK, SC, and JV.

Competing interests. The authors declare that they have no conflict of interest.

Acknowledgements. The authors acknowledge the financial support from the Public Scholarship, Development, Disability and Maintenance Fund of the Republic of Slovenia (contract no. 1101144/2016-18). The authors also gratefully acknowledge the Environmental Agency of the Republic of Slovenia for the permission provided for and the assistance in installing the weather instrument shelter for radon monitoring on their land and for providing the meteorological and air quality data.

Financial support. This research has been supported by the Slovenian Research Agency (research core funding no. P1-0143).

Review statement. This paper was edited by Robyn Schofield and reviewed by Roberto Salzano and one anonymous referee.

\section{References}

Allegrini, I., Febo, A., Pasini, A., and Schiarini, S.: Monitoring of the nocturnal mixed layer by means of particulate radon progeny measurement, J. Geophys. Res., 99, 18765-18777, 1994.

ARSO: Slovenian Environment Agency (Slovenian: Agencija Republike Slovenije za okolje), Climate Characteristics of Ljubljana - Wind Rose for the City of Ljubljana, 2017.

Avino, P. and Manigrasso, M.: Ten-year measurements of gaseous pollutants in urban air by an open-path analyzer, Atmos. Environ., 42, 4138-4148, https://doi.org/10.1016/j.atmosenv.2008.01.024, 2008.

Baasandorj, M., Hoch, S. W., Bares, R., Lin, J. C., Brown, S. S., Millet, D. B., Martin, R., Kelly, K., Zarzana, K. J., Whiteman, C. D., Dube, W. P., Tonnesen, G., Jaramillo, I. C., and Sohl, J.: Coupling between chemical and meteorological processes under persistent cold-air pool conditions: evolution of wintertime $\mathrm{PM}_{2.5}$ pollution events and $\mathrm{N}_{2} \mathrm{O}_{5}$ observations in Utah's Salt Lake Valley, Environ. Sci. Technol., 51, 5941-5950, https://doi.org/10.1021/acs.est.6b06603, 2017.

Beeston, M., Grgić, I., van Elteren, J. T., Iskra, I., Kapun, G., and Močnik, G.: Chemical and morphological characterization of aerosol particles at Mt. Krvavec, Slovenia, during the Eyjafjallajökull Icelandic volcanic eruption, Environ. Sci. Pollut. Res., 19, 235-243, https://doi.org/10.1007/s11356-011-0563-8, 2011.

Bielec-Bąkowska, Z., Knozová, G., Leśniok, M., Matuszko, D., and Piotrowicz, K.: High suspended dust concentrations in Brno, Sosnowiec and Krakow (the year 2009 as an example), Pr. Geogr., 126, 67-84, 2011.

Chambers, S., Williams, A. G., Zahorowski, W., Griffiths, A., and Crawford, J.: Separating remote fetch and local mixing influences on vertical radon measurements in the lower atmo- 
sphere, Tellus B, 63, 843-859, https://doi.org/10.1111/j.16000889.2011.00565.x, 2011.

Chambers, S. D., Hong, S.-B., Williams, A. G., Crawford, J., Griffiths, A. D., and Park, S.-J.: Characterising terrestrial influences on Antarctic air masses using Radon-222 measurements at King George Island, Atmos. Chem. Phys., 14, 9903-9916, https://doi.org/10.5194/acp-14-9903-2014, 2014.

Chambers, S. D., Williams, A. G., Crawford, J., and Griffiths, A. D.: On the use of radon for quantifying the effects of atmospheric stability on urban emissions, Atmos. Chem. Phys., 15, 1175-1190, https://doi.org/10.5194/acp-15-1175-2015, 2015.

Chambers, S. D., Podstawczyńska, A., Pawlak, W., Fortuniak, K., Williams, A., and Griffiths, A.: Characterising the state of the urban surface layer using Radon-222, J. Geophys. Res.-Atmos., 124, 770-788, 2019.

Chemel, C., Arduini, G., Staquet, C., Largeron, Y., Legain, D., Tzanos, D., and Paci, A.: Valley heat deficit as a bulk measure of wintertime particulate air pollution in the Arve River Valley, Atmos. Environ., 128, 208-215, https://doi.org/10.1016/j.atmosenv.2015.12.058, 2016.

Clements, C. B., Whiteman, C. D., and Horel, J. D.: Cold-air-pool structure and evolution in a mountain basin: Peter Sinks, Utah, J. Appl. Meteorol., 42, 752-768, https://doi.org/10.1175/15200450(2003)042<0752:CSAEIA>2.0.CO;2, 2003.

Cohen, L. D., Barr, S., Krablin, R., and Newstein, H.: Steady-state vertical turbulent diffusion of radon, J. Geophys. Res., 77, 26542668, 1972.

Cuxart, J., Holtslag, A. A. M., Beare, R. J., Bazile, E., Beljaars, A., Cheng, A., Conangla, L., Ek, M., Freedman, F., Hamdi, R., Kerstein, A., Kitagawa, H., Lenderink, G., Lewellen, D., Mailhot, J., Mauritsen, T., Perov, V., Schayes, G., Steeneveld, G.-J., Svensson, G., Taylor, P., Weng, W., Wunsch, S., and Xu, K.M.: Single-column model intercomparison for a stably stratified atmospheric boundary layer, Bound.-Lay. Meteorol., 118, 273303, https://doi.org/10.1007/s10546-005-3780-1, 2006.

Dorninger, M., Whiteman, C. D., Bica, B., Eisenbach, S., Pospichal, B., and Steinacker, R.: Meteorological events affecting cold-air pools in a small basin, J. Appl. Meteorol. Climatol., 50, 2223 2234, https://doi.org/10.1175/2011JAMC2681.1, 2011.

EEA: Air quality in Europe - 2016 report, 2016.

EEA: Air quality in Europe - 2017 report, 2017.

Etiope, G. and Martinelli, G.: Migration of carrier and trace gases in the geosphere: an overview, Phys. Earth Planet. Inter., 129, 185-204, 2002.

Eve, A. S.: On the amount of radium emanation in the atmosphere near the Earth's surface, London, Edinburgh, Dublin Philos. Mag. J. Sci., 16, 622-632, 1908.

Ferrario, M. E., Rossa, A., and Pernigotti, D.: Characterization of $\mathrm{PM}_{10}$ accumulation periods in the Po valley by means of boundary layer profilers, in IOP Conference Series: Earth Environ. Sci., 1, 012067, doi:10.1088/1755-1315/1/1/01206, 2008.

Galmarini, S.: One year of ${ }^{222} \mathrm{Rn}$ concentration in the atmospheric surface layer, Atmos. Chem. Phys., 6, 2865-2886, https://doi.org/10.5194/acp-6-2865-2006, 2006.

Goudie, A. S.: Desert dust and human health disorders, Environ. Int., 63, 101-113, https://doi.org/10.1016/j.envint.2013.10.011, 2014.

Griffin, D. W.: Atmospheric movement of microorganisms in clouds of desert dust and implications for human health, Clin. Micro- biol. Rev., 20, 459-477, https://doi.org/10.1128/CMR.00039-06, 2005.

He, T., Chen, Y., Stanič, S., Bergant, K., Gao, F., and Hua, D.: Properties of tropospheric aerosols observed over southwest Slovenia, J. Quant. Spectrosc. Ra., 217, 380-387, https://doi.org/10.1016/j.jqsrt.2018.06.009, 2018.

Highwood, E. J. and Kinnersley, R. P.: When smoke gets in our eyes: The multiple impacts of atmospheric black carbon on climate, air quality and health, Environ. Int., 32, 560-566, https://doi.org/10.1016/j.envint.2005.12.003, 2006.

Ivančič, $\mathrm{M}$. and Vončina, R.: Modelling $\mathrm{PM}_{10}$ dispersion from road traffic and industry in Ljubljana Basin, in: zbornik HARMO'15 konference, Madrid, 2015.

Jacob, J., Prather, J., Rasch, J., Beagley, R., Bergmann, J., Blackshear, W. T., Chiba, M., Chipperfield, M. P., Dignon, E., Kasibhatla, S., Kritz, M. A., Penner, E., Ramonet, M., Reeves, C. E., Stockwell, Z., Velthoven, F. J. Van, Verver, G., and Yang, H.: Evaluation and intercomparison of global atmospheric transport models using ${ }^{222} \mathrm{Rn}$ and other short-lived tracer, J. Geophys. Res., 102, 5953-5970, 1997.

Jędruszkiewicz, J., Czernecki, B., and Marosz, M.: The variability of $\mathrm{PM}_{10}$ and $\mathrm{PM}_{2.5}$ concentrations in selected Polish agglomerations: the role of meteorological conditions, 2006-2016, Int. J. Environ. Health Res., 27, 441-462, https://doi.org/10.1080/09603123.2017.1379055, 2017.

Kallos, G., Astitha, M., Katsafados, P., and Chris, S.: Long-range transport of anthropogenically and naturally produced particulate matter in the Mediterranean and North Atlantic: current state of knowledge, J. Appl. Meteorol. Climatol., 46, 1230-1251, https://doi.org/10.1175/JAM2530.1, 2006.

Karstens, U., Schwingshackl, C., Schmithüsen, D., and Levin, I.: A process-based ${ }^{222}$ radon flux map for Europe and its comparison to long-term observations, Atmos. Chem. Phys., 15, 12845 12865, https://doi.org/10.5194/acp-15-12845-2015, 2015.

Kassomenos, P. A. and Koletsis, I. G.: Seasonal variation of the temperature inversions over Athens, Greece, Int. J. Climatol., 25, 1651-1663, https://doi.org/10.1002/joc.1188, 2005.

Kirichenko, L. V.: The vertical distribution of the products of decay of radon in the free atmosphere, in Problems of Nuclear Meteorology, edited by: Karol, I. L. and Malakhov, S. G., State Publishing House for Literature in the Field of Atomic Science and Engineering, Moscow, 99-124, 1962.

Kochowska, E., Kozak, K., Kozłowska, B., and Mazur, J.: Test measurements of thoron concentration using two ionization chambers AlphaGUARD vs. radon monitor RAD7, Nukleonika, 54, 189192, 2009.

Kukkonen, J., Mia, P., Ranjeet, S. S., Lakhu, L., Nutthida, K., Lia, F., Minna, R., Erik, B., Viel, Ø., Leiv, H. S., Bruce, D., and Sandro, F.: Analysis and evaluation of selected local-scale $\mathrm{PM}_{10}$ air pollution episodes in four European cities: Helsinki, London, Milan and Oslo, Atmos. Environ., 39, 2759-2773, https://doi.org/10.1016/j.atmosenv.2004.09.090, 2005.

Langmann, B., Folch, A., Hensch, M., and Matthias, V.: Volcanic ash over Europe during the eruption of Eyjafjallajökull on Iceland, April-May 2010, Atmos. Environ., 48, 1-8, https://doi.org/10.1016/j.atmosenv.2011.03.054, 2012.

Lareau, N. P., Crosman, E., Whiteman, C. D., Horel, J. D., Hoch, S. W., Brown, W. O. J., and Horst, T. W.: The persis- 
tent cold-air pool study, Bull. Am. Meteorol. Soc., 94, 51-63, https://doi.org/10.1175/BAMS-D-11-00255.1, 2013.

Largeron, Y. and Staquet, C.: Persistent inversion dynamics and wintertime $\mathrm{PM}_{10}$ air pollution in Alpine valleys, Atmos. Environ., 135, 92-108, https://doi.org/10.1016/j.atmosenv.2016.03.045, 2016a.

Largeron, Y. and Staquet, C.: The atmospheric boundary layer during wintertime persistent inversions in the Grenoble valleys, Front. Earth Sci., 4, 70, 2016b.

Lehner, M., Whiteman, C. D., Hoch, S. W., Jensen, D., Pardyjak, E. R., Leo, L. S., Di Sabatino, S., and Fernando, H. J. S.: A case study of the nocturnal boundary layer evolution on a slope at the foot of a desert mountain, J. Appl. Meteorol. Climatol., 54, 732751, https://doi.org/10.1175/JAMC-D-14-0223.1, 2015.

Levin, I., Born, M., Cuntz, M., Langendörfer, U., Mantsch, S., Naegler, T., and Wagenbach, D.: Observations of atmospheric variability and soil exhalation rate of radon-222 at a Russian forest site. Technical approach and deployment for boundary layer studies, Tellus B, 54, 462-475, 2002.

Longlong, W., Stanič, S., Gregorič, A., Bergant, K., Mole, M., and Vučković, M.: Evolution of the planetary boundary layer in the presence of fog and plume, in: EGU General Assembly Conference Abstracts, 18, p. 15363, 2016.

Marcazzan, G. M., Vaccaro, S., Valli, G., and Vecchi, R.: Characterisation of $\mathrm{PM}_{10}$ and $\mathrm{PM}_{2.5}$ particulate matter in the ambient air of Milan (Italy), Atmos. Environ., 35, 4639-4650, https://doi.org/10.1016/S1352-2310(01)00124-8, 2001.

Mazur, J. and Kozak, K.: Complementary system for long term measurements of radon exhalation rate from soil, Rev. Sci. Inst., 85, 022104, doi/abs/10.1063/1.4865156, 2014.

Miranda, A., Silveira, C., Ferreira, J., Monteiro, A., Lopes, D., Relvas, H., Borrego, C., and Roebeling, P.: Current air quality plans in Europe designed to support air quality management policies?, Atmos. Pollut. Res., 6, 434-443, https://doi.org/10.5094/APR.2015.048, 2015.

Moritz, S.: imputeTS: Time series missing value imputation in R, $\mathrm{R}$ Packag. version 2.5, available at: https://cran.r-project.org/ package=imputeTS, last access: 11 August 2019, 2017.

Moses, H., Stehney, A. F., and Lucas Jr, H. F.: The effect of meteorological variables upon the vertical and temporal distributions of atmospheric radon, J. Geophys. Res., 65, 1223-1238, 1960.

Pak, M.: Ljubljana, in: Enciklopedija Slovenije, edited by: Javornik M., Mladinska knjiga, Ljubljana, 218-220, 1992.

Perrino, C., Pietrodangelo, A., and Febo, A.: An atmospheric stability index based on radon progeny measurements for the evaluation of primary urban pollution, Atmos. Environ., 35, 52355244, 2001.

Petkovšek, Z.: Dissipation of the upper layer of all-day radiation fog in basins, Zb. Meteor. Hidrol. Rad, 5, 71-74, 1974.

Petkovšek, Z.: Relief meteorologically relevant characteristics of basins (air land interactions in quasi-closed system), Z. Meteorol., 28, 333-340, 1978.

Petkovšek, Z.: The termination of air pollution periods in valley basins, Z. Meteorol., 35, 370-372, 1985.

Petkovšek, Z.: Turbulent dissipation of cold air lake in a basin, Meteorol. Atmos. Phys., 47, 237-245, https://doi.org/10.1007/BF01025620, 1992.

Pey, J., Querol, X., Alastuey, A., Forastiere, F., and Stafoggia, M.: African dust outbreaks over the Mediterranean Basin during
2001-2011: $\mathrm{PM}_{10}$ concentrations, phenomenology and trends, and its relation with synoptic and mesoscale meteorology, Atmos. Chem. Phys., 13, 1395-1410, https://doi.org/10.5194/acp13-1395-2013, 2013.

Pitari, G., Coppari, E., De Luca, N., and Di Carlo, P.: Observations and box model analysis of radon-222 in the atmospheric surface layer at L'Aquila, Italy: March 2009 case study, Environ. Earth Sci., 71, 2353-2359, https://doi.org/10.1007/s12665-013-2635$1,2014$.

Poberžnik, M. and Štrumbelj, E.: The effects of air mass transport, seasonality, and meteorology on pollutant levels at the Iskrba regional background station (1996-2014), Atmos. Environ., 134, 138-146, https://doi.org/10.1016/j.atmosenv.2016.03.059, 2016.

Podstawczyńska, A. and Chambers, S. D.: Radon-based technique for the analysis of atmospheric stability - a case study from Central Poland, Nukleonika, 63, 47-54, https://doi.org/10.2478/nuka-2018-0006, 2018.

Pope, C. A. and Dockery, D. W.: Health effects of fine particulate air pollution: Lines that connect, J. Air Waste Manag. Assoc., 56, 709-742, https://doi.org/10.1080/10473289.2006.10464485, 2006.

R Development Core Team: R: A language and environment for statistical computing, R Found. Stat. Comput. Vienna Austria, https://doi.org/10.1038/sj.hdy.6800737, 2008.

Rakovec, J., Merše, J., Jernej, S., and Paradiž, B.: Turbulent dissipation of the cold-air pool in a basin: Comparison of observed and simulated development, Meteorol. Atmos. Phys., 79, 195-213, https://doi.org/10.1007/s007030200003, 2002.

Reddy, P. J., Barbarick, D. E., and Osterburg, R. D.: Development of a statistical model for forecasting episodes of visibility degradation in the Denver metropolitan area, J. Appl. Meteorol., 34, 616-625, 1995.

Šajn, R., Gosar, M., Bidovec, M., Pirc, S., and Alijagić, J.: Geochemical mapping of Ljubljana urban and suburban area, Slovenia, in: Mapping the Chemical Environment of Urban Areas, 375-392, 2011.

Salzano, R., Pasini, A., Casasanta, G., Cacciani, M., and Perrino, C.: Quantitative interpretation of air radon progeny fluctuations in terms of stability conditions in the atmospheric boundary layer, Bound.-Lay. Meteorol., 160, 529-550, https://doi.org/10.1007/s10546-016-0149-6, 2016.

Salzano, R., Pasini, A., Ianniello, A., Mazzola, M., Traversi, R., and Udisti, R.: High time-resolved radon progeny measurements in the Arctic region (Svalbard islands, Norway): results and potentialities, Atmos. Chem. Phys., 18, 6959-6969, https://doi.org/10.5194/acp-18-6959-2018, 2018.

Satterly, J.: I. On the amount of radium emanation in the lower regions of the atmosphere and its variation with the weather, London, Edinburgh, Dublin Philos. Mag. J. Sci., 20, 1-36, https://doi.org/10.1080/14786441008636877, 1910.

Schery, S. D. and Huang, S.: An estimate of the global distribution of radon emissions from the ocean, Geophys. Res. Lett., 31, L19104, https://doi.org/10.1029/2004GL021051, 2004.

Sesana, L., Caprioli, E., and Marcazzan, G. M.: Long period study of outdoor radon concentration in Milan and correlation between its temporal variations and dispersion properties of atmosphere, J. Environ. Radioact., 65, 147-160, https://doi.org/10.1016/S0265-931X(02)00093-0, 2003. 
Silcox, G. D., Kelly, K. E., Crosman, E. T., Whiteman, C. D., and Allen, B. L.: Wintertime $\mathrm{PM}_{2.5}$ concentrations during persistent, multi-day cold-air pools in a mountain valley, Atmos. Environ., 46, 17-24, https://doi.org/10.1016/j.atmosenv.2011.10.041, 2012.

Szegvary, T., Leuenberger, M. C., and Conen, F.: Predicting terrestrial ${ }^{222} \mathrm{Rn}$ flux using gamma dose rate as a proxy, Atmos. Chem. Phys., 7, 2789-2795, https://doi.org/10.5194/acp-7-2789-2007, 2007.

Szegvary, T., Conen, F., and Ciais, P.: European ${ }^{222}$ Rn inventory for applied atmospheric studies, Atmos. Environ., 43, 1536-1539, https://doi.org/10.1016/j.atmosenv.2008.11.025, 2009.

Triantafyllou, A. G.: $\mathrm{PM}_{10}$ pollution episodes as a function of synoptic climatology in a mountainous industrial area, Enviro, Pollut., 112, 491-500, 2001.

Vardoulakis, S. and Kassomenos, P.: Sources and factors affecting $\mathrm{PM}_{10}$ levels in two European cities: Implications for local air quality management, Atmos. Environ., 42, 3949-3963, https://doi.org/10.1016/j.atmosenv.2006.12.021, 2008.

Vrhovec, T.: Analysis of mesometeorological temperature fields, Meteorol. Atmos. Phys., 43, 235-240, 1990.

Wang, F., Chambers, S. D., Zhang, Z., Williams, A. G., Deng, X., Zhang, H., Lonati, G., Crawford, J., Griffiths, A. D., Ianniello, A., and Allegrini, I.: Quantifying stability influences on air pollution in Lanzhou, China, using a radon-based "stability monitor": Seasonality and extreme events, Atmos. Environ., 145, 376-391, https://doi.org/10.1016/j.atmosenv.2016.11.003, 2016.

Whiteman, C. D., Eisenbach, S., Pospichal, B., and Steinacker, R.: Comparison of vertical soundings and sidewall air temperature measurements in a small Alpine Basin, J. Appl. Meteorol., 43, 1635-1647, https://doi.org/10.1175/JAM2168.1, 2004.

Whiteman, C. D., Hoch, S. W., Horel, J. D., and Charland, A.: Relationship between particulate air pollution and meteorological variables in Utah's Salt Lake Valley, Atmos. Environ., 94, 742753, https://doi.org/10.1016/j.atmosenv.2014.06.012, 2014.
WHO: Ambient (outdoor) air quality and health, available at: http://www.who.int/mediacentre/factsheets/fs313/en/ (last access: 26 November 2015), 2014.

Wickham, H.: ggplot: Using the grammar of graphics with R, New York Springer, 2009.

Wigand, A. and Wenk, F.: Der gehalt der luft an Radium-emanation, nach messungen bei flugzeugaufstiegen, Ann. Phys., 391, 657686, 1928.

Williams, A., Zahorowski, W., Chambers, S., and Griffiths, A.: The vertical distribution of radon in clear and cloudy daytime terrestrial boundary layers, J. Atmos. Sci., 68, 155-174, https://doi.org/10.1175/2010JAS3576.1, 2011.

Williams, A. G., Chambers, S., and Griffiths, A.: Bulk mixing and decoupling of the nocturnal stable boundary layer characterized using a ubiquitous natural tracer, Bound.-Lay. Meteorol., 149, 381-402, https://doi.org/10.1007/s10546-013-9849-3, 2013.

Williams, A. G., Chambers, S. D., Conen, F., Reimann, S., Hill, M., Griffiths, A. D., and Crawford, J.: Radon as a tracer of atmospheric influences on traffic-related air pollution in a small inland city, Tellus B, 68, 1-21, https://doi.org/10.3402/tellusb.v68.30967, 2016.

Wright, J. R. and Smith, O. F.: The variation with meteorological conditions of the amount of radium emanation in the atmosphere, in the soil gas, and in the air exhaled from the surface of the ground, at Manila, Phys. Rev., 5, 459-482, https://doi.org/10.1103/PhysRev.5.459, 1915.

Yao, W. and Zhong, S.: Nocturnal temperature inversions in a small, enclosed basin and their relationship to ambient atmospheric conditions, Meteorol. Atmos. Phys., 103, 195-210, https://doi.org/10.1007/s00703-008-0341-4, 2009.

Zhuo, W., Guo, Q., Chen, B., and Cheng, G.: Estimating the amount and distribution of radon flux density from the soil surface in China, J. Environ. Radioact., 99, 1143-1148, https://doi.org/10.1016/j.jenvrad.2008.01.011, 2008. 